\title{
ESTIMATING LONG-TERM STATISTICS FOR ANNUAL PRECIPITATION FOR SIX REGIONS OF THE UNITED STATES FROM TREE-RING DATA
}

Harold C. Fritts, Emily DeWitt, Geoffrey A. Gordon, John H. Hunt, and G. Robert Lofgren

\author{
Laboratory of Tree-Ring Research \\ University of Arizona \\ Tucson, Arizona 85721
}

Lawrence Livermore Laboratory Contract No. 3216209

December, 1979 


\begin{abstract}
FOREWORD . . . . . . . . . . . . . . . . . . . . . 1
ABSTRACT . . . . . . . . . . . . . . . . . $i i$

INTRODUCTION . . . . . . . . . . . . . . . . . 1

TREE RINGS AS PROXIES OF CLIMATIC VARIATIONS . . . . . 3

RECONSTRUCTING SPATIAL VARIATIONS IN CLIMATE . . . . . 7

Evaluating the Reliability of a Reconstruction . . . 11

Percent Variance Calibrated . . . . . . . . 11

Verification with Independent Data . . . . . . 12
\end{abstract}

MODEL SELECTION, AVERAGING, AND TESTING OF

THE ANNUAL RECONSTRUCTIONS . . . . . . . . . . . . 17

COMPARISON OF THE DEVELOPMENTAL AND FINAL

PRECIPITATION RECONSTRUCTIONS . . . . . . . . . . 19

Calibration and Verification Statistics... . . . 19

Comparisons of the Reconstructions over
Climatological Regions . . . . . . . . 20

COMPARISON OF TWENTIETH CENTURY OBSERVATIONS WITH

RECONSTRUCTIONS FOR THE SEVENTEENTH THROUGH

NINETEENTH CENTURIES . . . . . . . . . . . . . . 24

Frequency Distributions . . . . . . . . . . 24

The Statistics of Variations in Subperiods . . . . . 26

CONCLUSIONS . . . . . . . . . . . . . . . 28

RECOMMENDATIONS . . . . . . . . . . . . 30

FIGURES . . . . . . . . . . . . . . . 31

TABLES . . . . . . . . . . . . . . . 38

REFERENCES . . . . . . . . . . . . . . . . 46

APPENDIX 1A. Regional Time Series Analysis
Program Package . . . . . . . . 1-1

IB. Equations, Tables, and Figures . . . . . 1-17

APPENDIX 2. Statistics for Reconstructions by 25-Year, 100-Year, 300-Year, and 360-Year Intervals as Compared to 1901-1961 Statistics . . . 2-1 
FOREWORD

This paper presents an application of deadeqelimasologx, a discipline which uses the annual growth layers of trees (rings) to study past climate. This application has grown out of a 10-year project sponsored by the National Science Foundation, current grant ATM-77-19216, which is a long-term project ained at reconstructing past spatial patterns in climate from spatial patterns in tree growth. We have used the technology and reconstructions from this long-term project to calculate certaln climatic statistics for use in the Nuclear Regulatory Commission Nuclear waste Management Program. Details of the methodology used in this study are published elsewhere (fritts, Lofgren, and Gordon, 1979 ).

The application utilizes reconstructions of annual precipitation from 1602 through 1961, averaged over a number of precipitation stations in six climatic regions in the United States and southwestern Canada. The averaged reconstructions are then used to assess the long-tern means and the varlability of climate for 360 years. The computer software and selected results which were a part of this application are descrioed in the Apoendices. We wish to acknowledge Ann Marek, who helped efit and computer process this manuscript, and Dorothy Larson, who helped with the graphics for this report. The faclities of the university of Arizona Computing Center were used for this project. 


\section{$\triangle B S T Q A C T$}

Spatial anomalies of seasonal orecipitation for the United States and southwestern Canada have been reconstructed from 1602 through 1961 using dendrochronological and multivariate techniques on 65 arid-site tree-ring chronologies from western North America. Seasonal reconstructions are averaged to obtain mean annual precioitation values for six regions of importance to the Nuclear Regulatory Commission (NRC) Nuclear Waste Management Program (NWMP). Statistics calculated from the regionally averaged annul values for 25-year and longer intervals show annual orecioitation in the seventeenth through nineteenth centuries to be lower than in the twentieth century for three regions in the American southwest and higher for one region in the Vorthwest and two regions in the East. The variability of orecioitation generaliy was higher in the oast three centuries than in the present century. Twentr-five-year Intervals with noteworthy statistics are Identified and important results are sumnarized and tabllated for usa in the hydrologic modeling of the NWMP. Additional research is recommended to incoroorate temperature and pracioitation into a single hydrologic oarameter. 


\section{INTRODUCTION}

The climate of North America during the 1930's through $1960^{\prime} s$ has been unusually mild in certain localities and as such is not representative of conditions in the longer-term Dast (Bryson and Hare, 1974). Therefore, the climatic suitability of sites belng considered by the NwMp should not be evaluated exclusively with existing neteorological records. Climatic parameters should be assessed in terms of more representative long-term climatic information. proxy records (substitutes for neteorological data) can be used to extend our knowlesge of climate backward in time laarry et 31., 19791. The extended record allows ar assessment of oast climatic variations and can be used to olace the twentieth century anomalies in proper persoective.

There are many tyoes of proxy records of climate, but most of them cannot be resolved into variations of less than 100 years (Barry et a1., 1979). Layers in some lake sediments and glacial ice may approximate annual insenents, but the layers cannot be reliably dated to the exact year of formation. In addition, the availability of many oroxy lata is restricted to relatively few localities over the world. Tree-ring chronologles, however, overcome those orotens. They are generally arailable in all temperate and subarctic 
forestes regions, and they have a more orecise time resolution with dating possible to the exact season andior year (Fritts, 1976). Historical data on climate also have a sinilar time resolution. sometimes to the exact moment an event occurred. But unlike tree rings, they can reflect subjective interpretations of past events and lack continuity over both soace and time.

Thls oaper reviews how climatic information can be derived from well-dated tree-ring records and used to assess oast variations in climate. Reconstructions of dast orecipitation varlations are described and applied to questions of interest to the NWMP. Statistics of climatic variations in six selected regions of the United states and southwest Canada are analyzed in time increnents of 25 years from $\triangle D 1602$ through 1961 and compared to twentieth century normal"data. 
TREF RINGS AS PROXIES DF CLIMATIC VARIATITVS

Generally, one growth ring is formed each year in temperate-climate trees, and its width can vary as a function of different limiting factors, including climate. The size, structure, and chemical composition of these rings orovide climatic information only when the tree arowth has been limited in sone way by one or more factors of cllmate throughout a portion of the year (Fritts, 1976; LaMarche, 1974, 1978; Stockton and Meko, 19751. The skilled dendroclimatologist can recognize and select trees with ootential climatic information from the structure of the tree crown and trunk and from the apoearance of the rings. The rings of the selected trees are sampled br neans of a coring tool which extracts a pencil-sized culinder of wood from the trunk. A complete samole often includes cores from 10 to 25 climate-stressed trees arowing on similar sites in a local area. The cores are processed to feternine the width and detalled structure of the annual growth lavers. Because nonclimatic factors can obscure the effects of climate, the rings are exanined, studied carefully, and screened for such problems before they are dated and neasured. 
In years oarticularly unfarorable to growth, the rings are narrow, and in some trees no ring is formes at all. In other seasons, an unusual period of drosght Juring the growing season may cause some trees to prodsce nore than one ring for that year. These factors can nake datino difficult. Therefore, just as simple counts of layered sediments and ice cores are unreliable, a slmole count of the rings from the outside to the center of a living tree is an unreliable method for dating the formation of ach ring. - more reliable dating technique, called acossating, uses identifiable ring patterns which are characteristic of unique time periods, with each period exhibiting a oarticular sequence of climatic conditions.

Using these identifiable ring patterns, the size and appearance of rings are matched with those in other trees from the same collection site to locate imorooerly interpreted growth rings that cause the ring oatterns for that site to be nonsynchronous. Some tyoes of discreoancies among trees indicate that no ring is visible on the sanole and other types Indicate the presence of a fouble or false ring. These discrepancies are identifies ant eorrections are nade for them. When all ring sequences are matched correctly, an accurate date is assigned to each ring before measuring the widt. 
The crossdating procedure is tedious and tine-consumino, but It is an essential oart of all dendroclinatological work. Because of the demonstrated accuracy of erossdating (Lamarche and Harlan, 1973), dendroclimatology can deal with precisely dated varlations in growth patterns over both soace and time.

The use of the ring-width data in a climatological study requires the removal of any variabllity in the ring widths that is not climatically induced. One well-recognized nonclinatic factor is a decrease in ring idth with increasing tree age. This systematic change in ring width is ellminated using a procedure called standardization, in wich each measurement of ring width for a particular year is divided by the expected grouth for that tree and age on the particular site (fritts, 1976; LaMarche 1978). The standardized values are then averaged with those of the other sampled trees from the same site to obtain nean yearly values of growth relative to the tree's age. Trus, a tree-ring chronology is formed as the mean time series of the standardized yearly ring widths for a orticular sanole of trees Ifritts, 1976; LaMarche, 1974; Stockton and Mako, 19751 
More than a thousand chronologies are now available from North american conifers, and collecting, research, and analysis programs have begun in wost temperate regions of the world (LaMarche, 1978). We have selected 65 of the best chronologies from western North America for our particular analysis (Fig. 1) (Fritts and Shat?, 1975). Each chronology represents a sample of two cores each from 10 or more trees of one of the following species: Douglas-fir (eseudotsuga menzlesti), bigcone-spruce (P. magegaroa), oonderosa pine (pigus geadecesa), oinyon pine (pe edulls),

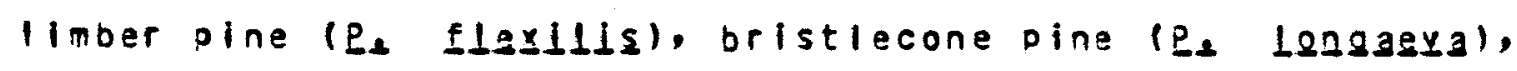
Jeffrey oine (P, jeffreyl), and white fir (Abies eageoler). 
PECONSTRUCTING SPATIAL VARIATIONS IN CLIMATE: CALIBRATION

The climate-growth relationship is highly comolex and is ooorly understood in detall. Tree grouth resoonds to many climatic factors whose influence on growth, and hence the chronologies, can vary trroughout the year (Fritts, 1974, 1976). The diagram in figure? lllustrates sone of the complexities in the growth resoonse in which the sllate for year 5 may include factors such as tenperature, orecioitation, sunshine, and wind, which vary in their Importance throughout the winter, spring, summer, and autumn months.

The growth layer is formed in the spring ant summer and may be directly affected by climate during that tine. During autumn and winter, the so-called seasors of dormancy, climatic factors have important effects on soll molsture recharge, profuction and storage of food in the tree, and root growth. In addition, there are many lagoing effects of climate during year $I$ which can affect grouth in the succeeding years $t \pm l$ through $5 \pm \underline{x}$ shown in fiaure?. The climate in the preceding year, $t=1$, may not only influence the following year's ring width, but may also control the formation of laves and roots which are in turn pelated to the efficiency of the tree in the following years, $t, \pm \pm I$, 
through $5 \pm x$. This oroduces an autocorrelation in the chronologies where narrow rings tend to befollowed by narrow rings, even though the climate of the second vear was favorable to growth (FIg. 2). All of these interrelationships should be considered when the climatic information for a particular year is extracted from ring-width data.

Because of the comolexities in the clinate-growth relationship, maps of climatic varlations made by simole deduction from mas of tree-growth anomalies (fritts, 1965 , $1976)$ can only be considered as unrefined ropresentations of past climate. Dendroclimatologists now recojnize the complexity of the system they are dealing with, and nultivariate regression techniques are employed to decode the climate information contained in the chronologios (Fritts, 1976; Fritts et 11., 1971; Webb and Clark, 1977). The use of multivariate techniques al lows individual climatic factors to be oortrayed in a direct manner.

Figure 3 depicts how the multivariate regression techniaues are used to obtain estimates of climatic paraneters. In essence, lagged ring-width measurenents $\left(x^{15}\right)$ are compared to climatic observations, and from these comparisons, coefficients (b's) are obtalned. In this manner, the ring 
widths are calibrated with the climatic observations. The products of the coefficients and ring widths are then summed to produce the estimate of the clinatis parameter. The resultant calibration equation can then be aoolled to ping-width measurements for past years to reconstruct the climatic conditions resoonsible for the observed oatterns in growth. The actual calibration procedure is comolex and is described in detail elsewhere (8)asing, 1979; Fritts, 1976; Fitts, Lofgren, and Gordon, 1979 ).

It must be noted that the coefficients derived in this manner are unique for each climatic record and chronology that are compared in the calibration procedure. In tris paper the years 1901 through 1962 are used as the calibration period, the oeriod for which there are both tree-ring and meteorological observations. The use of a fifferent calibration period would alter the derived coefficients and hence the estimates of oast climate. The oerlod 1901-1962 represents the longest calibration deriod possible and, therefore, should produce the nost stable climatic estimates.

Calibrations are individualiy made for each climatic variable and season, but are collectively nade for a number of climatic stations arranged in a grid natwork. Because 
climate is soatially continuous it can be correlated over large areas. Therefore, the climatic grids can extend well beyond the region covered by the tree-ring chronologies. This spatial continuity of climate and the ability to estinate climatic variables over large areas has been studied by Kutzbach and Guetter (in oress).

The set of 65 western tree-ring chronologies (fig. 1) was calibrated with three climatic variables for four seasons and over several grids. These grids were: 1) ob points of sea level pressure covering an area from $30^{\circ} \mathrm{W}$ to $100^{\circ} \mathrm{E}$ longltude and from $20^{\circ} \mathrm{N}$ to $70^{\circ} \mathrm{N}$ latitude, 2177 temoerature stations in the United States and soutrwestern canada, and 3) 96 precipitation stations over the same area used for temperature. The seasons used fere: winter: Decenber-february; soring: March-June; sumer: July-August; and gutumn: September-November. The 96-station orecioltation grid was used for this reoort.

Thus, the tree-ring chronologies were transformed into estinates of each climatlc variable for eash season and for each station in the grid for the oeriod 160?-1900. The time series of estimates at each station is collectivelv called the reconstruction. The oatterns in past climate oresent in these reconstructions can be portrayed for each season anc year by the preoaration of maps, the plotting of tine serles, and the presentation of descriotive statistics. 
EVALUATING THE RELIABILITY OF A RECONSTRUCTIDN

The types of lagged relationshios that are combined in a regression equation can be varied, and some equations may result in more reliable estimates of climate than others. secause the best combination of climate estimators cannot be chosen a ecieri, a number of reconstructions are nade using different combinations of lagged estimators. It is then necessary to use an objective aporoach to select the nost reliable reconstruction. A first approximation of the rellability of a reconstruction can be obtained by examining certain statistics calculated over the period of calibration from the reconstruction and the actual tata. The most important of these statistics is the eereant yaclages calibrated.

PERCENT VARIANCE CALIBRATED

The percent variance calibrated is the percent of the total variation, in the actual climatic data that is accounted for by the reconstructed climatic data within the calibration oeriod. A percent varlance callorated that is too low indicates that the oarticular combination of clinate estinators used is a poor choice because the resulting reconstruction contains little information about the actual 
climatic variations that occurred. The oereent variance caliorated can be increased by making better combinations of climate estimators, but it can be artificlally increased by making the combination too complex. The penalty for having too complex a mojel is a reconstruction which, while closely matching climatic variations in the calibration oerlod, is highly susceptible to large errors in climate estimates nade for vears outside the calibration oeriod.

A truly reliable reconstruction is one that oerforms well both on the calloration data and on indeperdent lata, i.e., data not used in calibration. Ultimately, the only means of determining the true reliablilty of a reconstruetion is to compare it to independent climatic information.

VERIFICATION WITH INDEPENDENT DATA

The independent climatic information used for verification can include meteorological measurements, oroxy information including tree-ring chronologies not used in the calioration, and various tyoes of historical evidence. Each type of information has its strengths and weaknesses, and all three can be used to verify different features of the reconstructions. 
Veriflcation with independent meteorological measurements is the most objective and precise nethod of testino reliability, and for that reason it has the greatest scientific value. Independent meteorological measurements are compared directly with the reconstructions on a station-by-station basis and the similarity measured with five objective statistics (Fritts, Lofgren, and Gordon, 1979 ) that are tasted for signiflcance at the $95 \%$ level (Table I). The results are expressed as the percentage of stations passing each test. A percentage of tests passing that is greater than the $5 \%$ expected by chance suoports the contention that the reconstruction does contain valid climatic information. It should be noted, however, that these five statistics neasure only the sinilarity in the temporal patterns of varlation and do not take into account the magnitude of the errors. A sixth statistic, the ceduction of erger (Lorenz, 1956; Fritts, 1975), reflects the magnitude of the errors or differances between the estimates and the actual measurements. The reduction of error (RE) is calculated for each station as follows:

$$
R E=1-5 S R / S S M
$$

where $S S E$ is the sum of the squares of the errors, and $S S M$ is the sum of the sauares of the deviations of the actual tata from the mean value during the calloration ogriod. The interpretation of RE can be quite comolicated, but in ossence, RE reoresents a comparison between the mean square error of the estimates and the nean square error obtainet if 
the calibration period mean had been substituted for the estinates (Kutzbach and Guetter, in oress; Lorenz, 1956).

The RE statistic can range from minus infinity to a maximum value of one. A value of one indicates a perfect prediction and a value of zero demonstrates that on the average the oredictive skill of the calibration equation for an individual year is no better than the predistion using the calioration perlod mean. Any positive value of RE clearly indicates that the predictive equation has some skill and that the reconstruction is of value. The value of $P E$ is hroersensitive to small errors, however, and oositive values nay be ruled out by only a few bad estimates. Recause of this sensitivity positive RE statistics are fifficult to obtain in practice, and situations often arise in wrich a station may have a negative RE statistic and yet still oass 3 majorlty of the other verification tests.

The six statisties described thus far are obtained for individual stations. It is also desirable to have verification statistics which describe the performance of the reconstruction at all the stations collectively. This Is done by combining the station sums in the pe calculations and thus obtaining a pooled reduction of error statistic. In recognition of the hypersensitivity of $R E$ to small errors 
and the fact that we cannot identify the ause of negative ZE statistics at individual stations, tre estimates at any station which had a negative RE are replaced by the calioration mean prior to pooling with the suns at other stations. This procedure has the effect of comoromising the reconstructions because the estimate errors for many of the vears tested were certainly less than those obtained by using the mean as a substitute estimate, bat at the same time the effect of any extreme errors is eliminated. This oooled RE statistic is reoorted here for the reconstruction over all stations collectively.

A second overall test of the reconstruction is made by pooling the independent estimates and observations for all rears and stations. A contingency table of nine equally probable classes is then constructed and tested using the chi-square statistic (Panofsky and grier, 1765$)$.

The statistics for the independent oerios are usually lower (less often significant) than those for the calibration oeriod. In part this is unfoubtedly the result of overspecification, but other sources of error 3150 exist. one such source is inherent errors in the early meteorological data used for verification. 4 careful sereening and checking of all meteorological data uset in 
the calibration period was made (Dewitt, 1979), but adequate records, time, or resources were not availasle to review tha Independent data from the nineteenth century. Therefore, many errors are likely to be present in these early data. Some uncertalnties due to different times of observation, kinds of instruments, exposures, and general lack of quality control over collection and transcriotion rave been identified (kennedy, in preparation). The fallures of indeoendent verification tests may be attributed to these types of errors as well as to poor climatic reconstruction. 
MDDEL SELECTION, AVERAGING, AND TESTING

OF THE ANNUAL RECONSTRUCTIONS

The data for this report were obtained as follows:

1) Callibrations were optimized for the 76 orecioitation stations for each season by a canonical stepwise multiole regression procedure (Frltts, Lofgren, and Gorton, 1979). The resultant reconstructions were then verlfied using independent data. The model structure was varled as to the number and combination of lagaing relationshios used. The best structure for each season was selected based uoon both the calloration and verification statisties. Two to three of the best models were combined by averaging their reconstructions, and new calibration and verification statistics were calculated. There was generally some improvement after averaging, thus the final motels chosen for each season vere combinations of two to three separate callorations. Earlier developmental reconstructions used by potter (1979) were chosen using callbration statistics alone without the aid of verification. Therefore, the developmental reconstructions are likely to contain overspecification and more serlous errors in the 1502-1900 interval than in the final reconstructions ased here. 
2) The four seasonal reconstructions were then totaled to obtain the December-Novenber annual reconstruction. Each annual reconstruction was assigned the year of the January month. The callbration and verification statistics for the annual reconstruction ishown in rable Il wa re obtalnes by comparisons with the corresponding monthiy meteorological data pooled in the same manner. 


\section{COMPARISDN OF THE DEVELOPMENTAL AND FIVAL \\ PRECIPITATION RECONSTRUCTIONS}

\section{CALIBRATION AND VERIFICATION STATISTICS}

Selected values of these statistics for both the developmental and final model are included in Table II. It should be noted that the oercent variance alibrated loses Its precise meaning for averaged reconstructions such as the annual results presented here. However, the sauare of the pearson correlation coefficient between the reconstructed annual values and the actual annual values for the period 1901-1762 can be interoreted as the oercent variance calibrated for the annual models (Table II). soth reconstructions were subjected to verification tests made on both the independent and deoendent (ealibration) periods. There were 84 of the 95 orecioltation stations tested, each with seven or more years of indeoendent data with an averace length of 26 years. For the final nodel, 197 of all the verification tests on indeoendent data were significant, and 88\% of the tests were significant for the calibration period (Tables I and II). 
The developmental model accounted for $50 \%$ of the calibration variance, possibly the result of oversoesification, while the final, more conservative model calibrated 25 s of the variance (Table II). Significant verification statistics increased from 15\%, for the developmental motel to $19 \%$ for the final model, and oercent posltive raduction of error statistics increased from 37\% to 52\%. The sooled reduction of error statistics were 0.10 and 0.12 for the develoomental and final models. The chi-square values were 101 and 176 for the two models, and these values are well above the value of 83 expectes by chance at the $95 \%$ probability level. These data indicate that the final model apoears to be an improvement over the developmental model even though there is less variance calibrated.

COMPARISONS DF THE RECONSTRUCTIONS OVER CLIYATOLOGICAL REGIONS

The 96-station precioitation grid was diviled into 11 climatological regions (fig. 4) and the resonstructions and observational data averaged over the stations in each region. These regions were chosen to be of comoarable size and to contain nearly equal numbers of stations. 
six of these regional reconstructions were selected to be of possible interest to the NWMP. The names and grid numbers of the selected regions shown in figure 4 are also 1 isted in Table III. Forty-two of the stations chosen for detalled study in these six regions had sufficient indedendent data lat least seven yearsl for verification.

One important attrioute of these reconstructions is that some of tre small-scale and hiah-frequency variations have been eliminated by the calibration process. In addition, some of the variability among the 96 precloitation stations Is eliwinated when the reconstructions are averaged by region. However, the amounts of correlated variance between the meteorological data and reconstructions apoear to Increase for the final reconstruction when the statistics are tabulated by region in rable IV for both the develoomental (1) and final reconstructions (2). Pow 4 contains the percent variances calibrated averaged for all stations included in the region. Next, the averaged reconstructions and observational data in each ragion were correlated, and the sauare of the correlation coefficient times 100 shows the relative agreement between the regional reconstructions and actual data loow 51. These reglonal data wereflitered using a lon-pass dialtal filtar with a 50\% pass at a frequency of one cycle per eigtit years (Fritts, 1976). The filtered reconstructions and 
meteorological data for each region were correlated, ant the sauare of the correlation coefficient times 100 was ajain used to measure the agreement after filtering (20u 6). The change from Row 4 to 5 measures the effect of regionalizing the reconstructions on the amount of agreenent with actual data, and the change from sow 5 to 6 reoresents tre additional effect on the agreement of removing fluctuations at frequencies higher than one cycle per eight years. In moving from pow 4 to Row 6 the total anount of variance Jecreases, but the percentage of agreenent between the reconstructions and actual data time serles increases. Row 7 is the percentage change between Rows 4 and 6 due to the soace and time averaging.

The percentage figures for Region 1 inficate that the develoomental model calibrated $51 \%$ of the variance for Individual stations, but the regionally averaged reconstructions showed 59\% agreement. After filtering, the agreement increased to 78\%, which is a 53\% change due to both space and time averaging. However, the final model $(2)$ calibrated less variance for the individual stations because the more rigorous selection reduced the anount of overspecification in the model structure. On the other hand, the relative improvement of agreament tue to both soace and time averaoing increased by 1?1\%. Similar comparisons for the statistics of other regions show ooor 
initial calibration but a greater percentage improvenent after space and time averaging, except in the case of the Southwest Deserts. In general, the reglonal data for the Intermountaln Basins show the highest agreenent whlle the data for the southeast show the lowest agreement.

The percent of veriflcation tests oassed (20w9, Table IV) was larger for the final model for four of the six regions. The correlation squared (ROH 9) was greater for the final nodel in all cases. The pooled redsction of error statistics (Row 10 ) were preater in the final model for half of the regions.

The final reconstruction appears to be superior to the developnental reconstruction when tested with independent tata, but on a region-by-region basis, the develoomental reconstruction seems to be superior for Regions 3 and 10 (Intermountain Basins and Southeast). In the remaining portions of this paoer we present and deseribe the results of only the final reconstruction. However, for analvses of the Intermountain Basins and the southeast, the reconstructions subnitted earlier and described by potter (1979) might be qqually valid. 


\section{COMPARISON OF TWENTIETH CENTURY OBSERVATIJNS \\ WITH RECONSTRUCTIONS FOR THE SEVEVTEENTH \\ THRDUGH NINETEENTH CENTURIES}

FREQUENCY OISTRIBUTIONS

To facilitate comparisons between the slimate of the twentieth century and that of earlier centuries, it was necessary to adjust the varlance and means of the reconstructions. The reconstructions are derived by means of nutiple regression techniaues which reduce the reconstructed variance in oroportion to one minus the square of the correlation coefflcient. For examole, the nean ratio between the standard deviation for the actual clinatic data for the 11 regions and the reconstructions for 1901-1961 is 2.12, i.e., the standard deviation of the actual data is, on the average, 2.12 times that of the reconstructed. The method of adjustment used here ldescribed on oge 1-11, Appendix IAl forces the reconstructed variance to equal the variance of the actual observations for the calibration period. The adjustment is thus apolied to the indeoendent period increasing the range of the reconstructed variations. 
The actual neteorological data and the reconstructions were then sorted into equal-sized orecioitation classes and the Prequency of occurrence in each class tabulated. This 3llows comparisons of the adjusted reconstructions for the 1901-1961 period with the actual meteorological measurements and with adjusted estinates for the 1502-1951 period. Figures 5,6 , and 7 show the class interval frequency Iistributions for 1) adjusted reconstructions for 1602-1961, 2) adjusted reconstructions for 1901-1961, and 31 observed neteorological recoros for 1901-1961. Table V includes the Prequencies of the adjusted reconstructions for 1602-1961, 1901-1961, 1901-1930, and 1931-1960. There is general agreement between the observed and reconstructed orecipitation for the 1901-1961 interval, although there are some differences. In the three arid regions (Regions 3,4 , and 61, the data are skewed because of one esoecially wet year which was not well reconstructed (figs, 5 and 5 ).

The reconstructions for 1301-1961 can be comoared to the reconstruction for 1602-196? to assess the relative cranges due to the larger sample of climatic varlations (Table $V$ ). The Columbia sasin, the Great Lakes and Midwest, and tre Southeast all show an increase in frequency of wet years in the longer time period, and in the Columbia sasin there is a decrease in the low precioitation classes but not the extrenely dry class. The Intermountain Basins and the 
Southwest Deserts show narked increases in the frequencles of dry years and a decrease in the frequencles of wet years in the longer time period. The reconstrsctions for the southern plains show little overall difference in the two time periods.

THE STATISTICS OF VARIATIONS IN SUBPERIODS

The reconstructions were analyzed over subperlots of 25 years, 100 years, and the entire 1602-1961 derlod (see 4ooendix 2, Tables 1-18). The means and standard deviations for three "control" oeriods (1901-1961, 1901-1930, and 1931-1960) (see Appendix 1A, p. 1-11) were compared to the means and standard deviations for each suboeriod. Table VI summarizes sone of the more outstanding differences. The mean for 1901-1930 was smaller than the man for 1001-1961 only for Regions 1 and 10 . For Regions $3,4,6$, and 9 the means for 1931-1960 were smaller than tre 1901-1930 nean. The standard deviations for 1901-1930 are sialler than for 1931-1960 in Regions 3 and 6 . They are larjer for the other regions when comparing the same subperiods. 
As shown in the frequency distribution (fias. 5,5 , and 7 ), the mean precioltation was higher for 1602-1961 than for the 1901-1961 control period in Reglons 1,9 , and 13 and lower in Regions 3, 4, and 6. The standard deviations for this longer interval were substantially larger for all regions. Some differences occur due to variations in the statistics of the three control oeriods.

The highest and lowest 25 -year statistics are also oresented along with their departures from the three control oeriods. The information in Table VI and the tables in the sooendices can be used to estimate some of the variations in climatic extremes that can occur based upon a 360-year-long record. The sample provlded by the reconstruction is five to six times as large as the available clinatic record from the same area. Secause of the larger sample slze, the derived statistics can be considered to be a more reliable estinate of long-term expectations than the statisties for the shorter twentieth century neteorological reoord. 


\section{CONCLUSIONS}

To aid in the assessment of climatic effects on ground water recharge and ultinately on the oerformance of proposed waste repositories, we have apolied the techniques described herein and in Appendix 1 to six regions of the united States. These reconstructions of climate show that the oast annual precipitation of Region 1 (Columbia Basinl, pegion? (Great Lakes and Midwest), and Region 10 (Southeast) was estinated to have been substantially hiqher in the seventeenth through nineteenth centuries than in the 1901-1961 period. On the average, precipitation was 210 to $320 \mathrm{~mm}$ greater for at least one 25-vear Jeriod in these regions, and no lower than 20 to $60 \mathrm{~mm}$ below the twentieth century average for any one 25-year perlod.

Pegion 3 (Intermountain basins), Reglon 4 (southwest Deserts), and Region 6 (Southern Plalns) were reoonstructed to have been considerably trier in the 1502-1900 oeriod than in the twentieth century (Table VI). In Region 4, all 25-year average precipitation values were 5 to $55 \mathrm{~mm}$ below the 1701-1961 averages. In Region 3 the average values ranged from $49 \mathrm{~nm}$ above to $54 \mathrm{~mm}$ belod the 1901-1961 averages, and in Region 6 the average values ranjed fron 36 min above to $63 \mathrm{~mm}$ below the 1901-1961 valses. Regions 1 
29

(columbia sasin), 9 (Great lakes and Midwest), and 10 (Southeast) were reconstructed to have been wetter in the 1602-1900 period, and the are rage values within that period ranged from $323 \mathrm{~mm}$ above to $63 \mathrm{~mm}$ below the 1901-1961 values.

Standard deviations were higher on the average for most time periods within the seventeenth through nineteenth centuries than they were for the twentieth century. In addition, as the average reconstructed orecioltation increased in the past, the standard deviations of the reconstructions also became higher. 


\section{RECOMMENDATIONS}

Temperature variations in the four seasons can influence evapotranspiration and deplete moisture near the soil surface before it enters the deeper layers, of the aquifer, reducing the amount of recharge. Therefore, tetter assessments of the effect of climatic varlations on aquifer recharge would be made bv direatiy estimating evapotranspiration. This could be acconplished by converting monthly temperature and orecioitation into evapotransplration using the Thornthwaite water budget (palmer, 1965). After subtracting evapotransolration, the remainder could be used as an index to the mount of water entering the hydrologlc system. These values can be calibrated directly with the tree-ring data as was done for orecioltation, and yearly reconstructions used to assess oast fluctuations in the aquifer recharge. Calculations of this kind would be better calibrated with tree rings than annual precipltation because tree rings reflect variations in the water balances of the tree system more than they reflect precipitaton measurenents. 


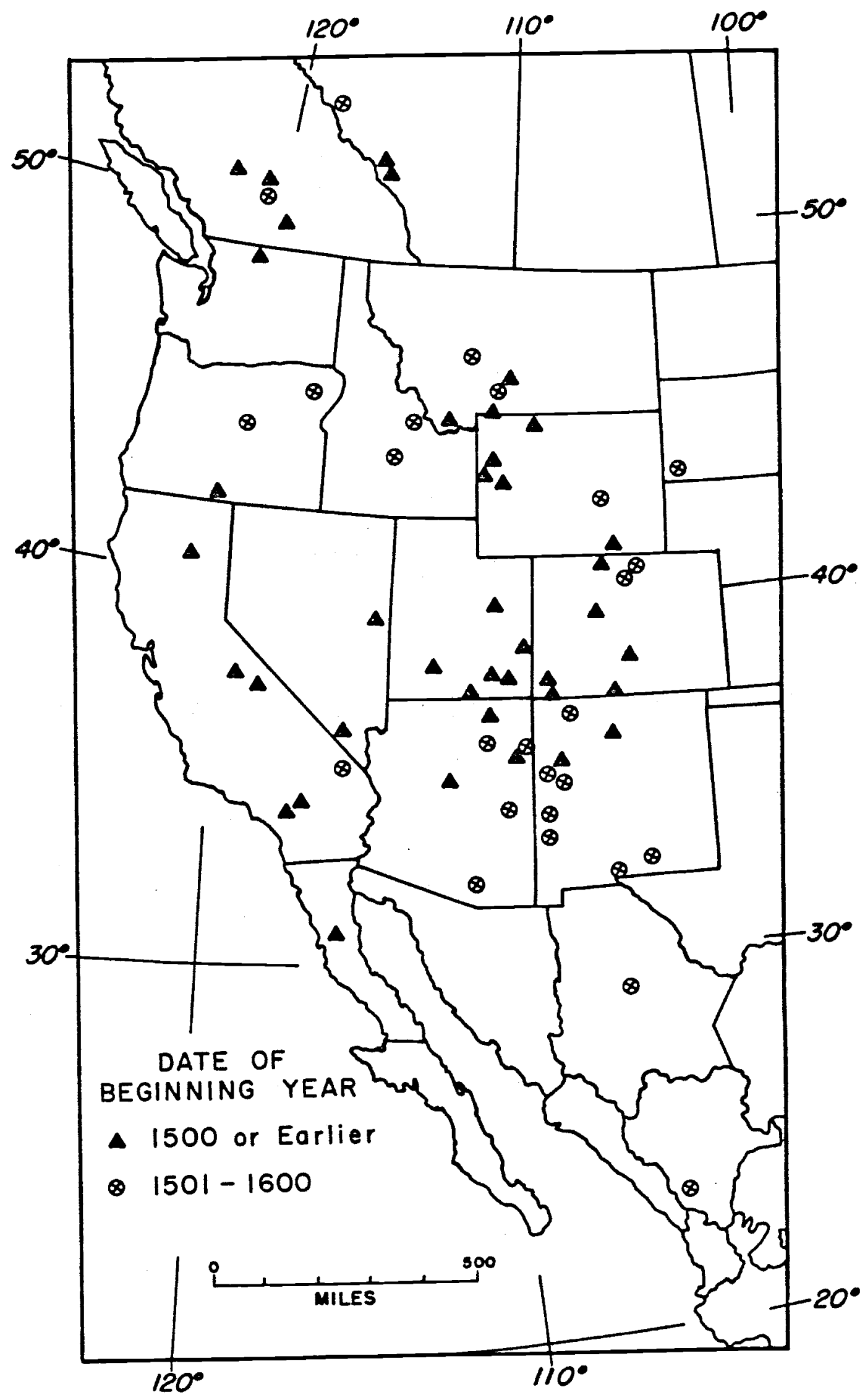

Figure 1. The 65 tree-ring chronologies used to reconstruct climate. 


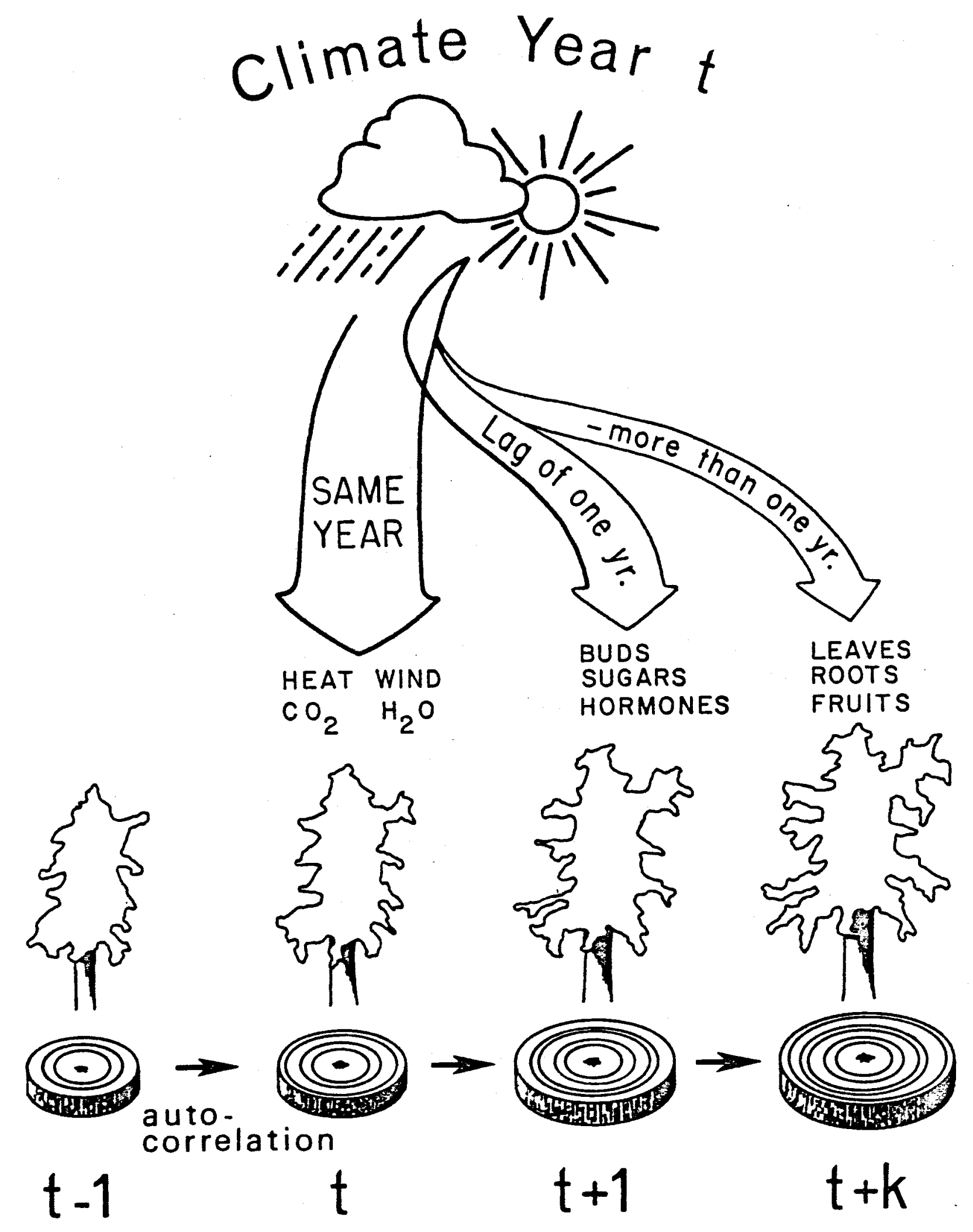

Figure 2. A model of the tree-ring width response to the limiting effects of year $t$ climate. 

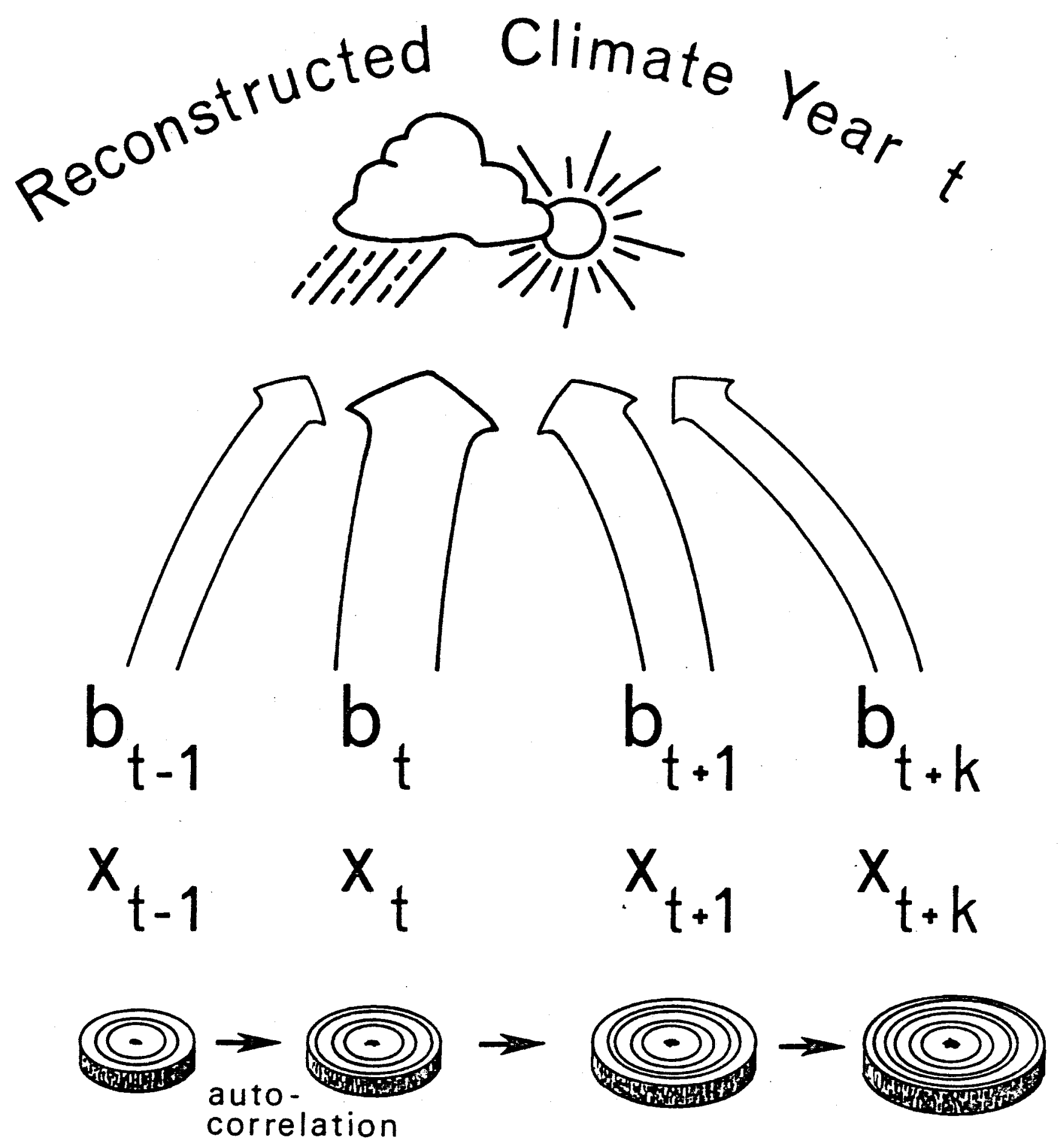

Figure 3. A multiple linear transfer function with coefficients ( $t$ ) used to transform ring widths in years $t-1$ to $t+k$ into estimates of year $t$ climate. 


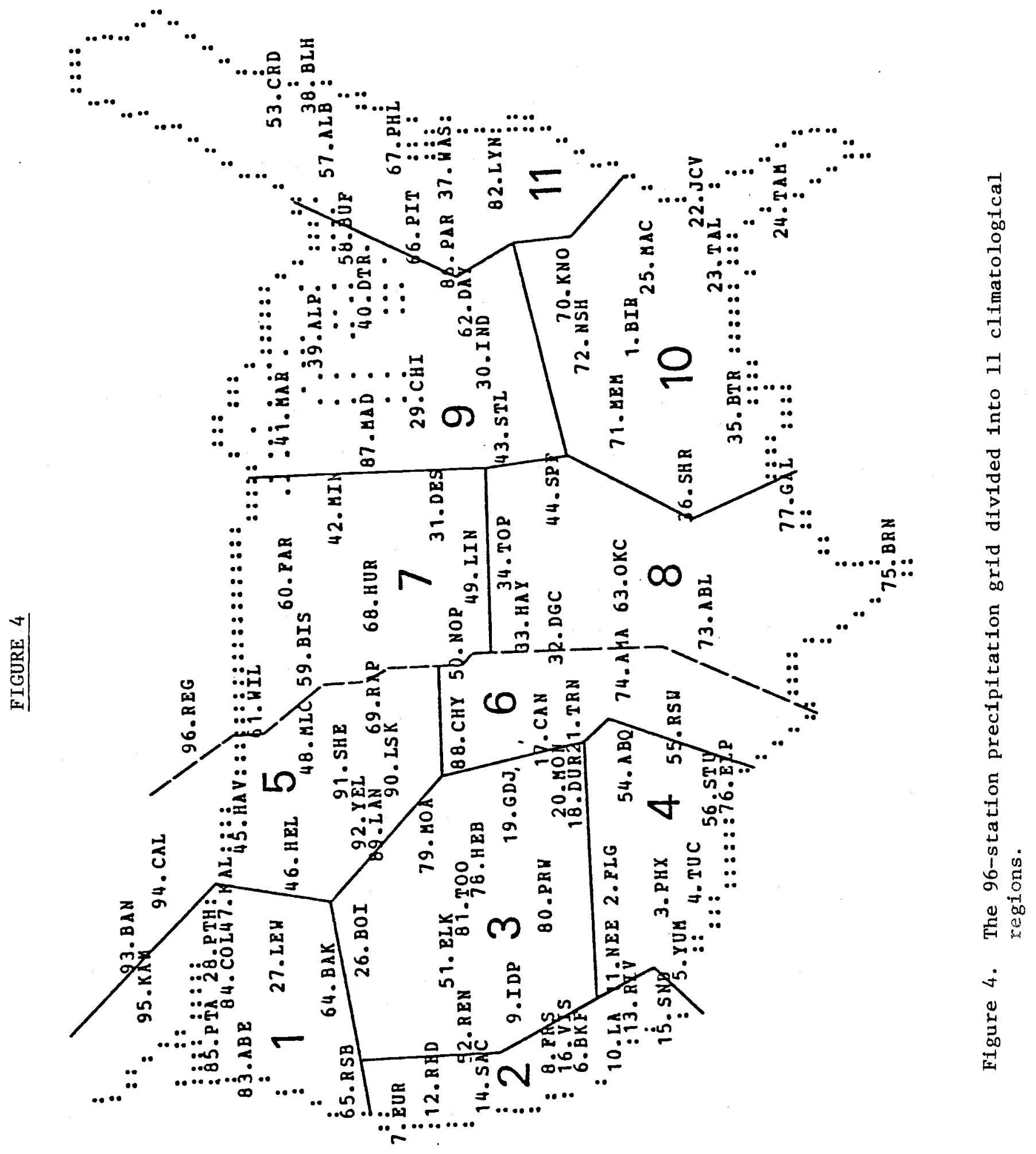




\section{REGION 1, COLUMBIA BASIN}

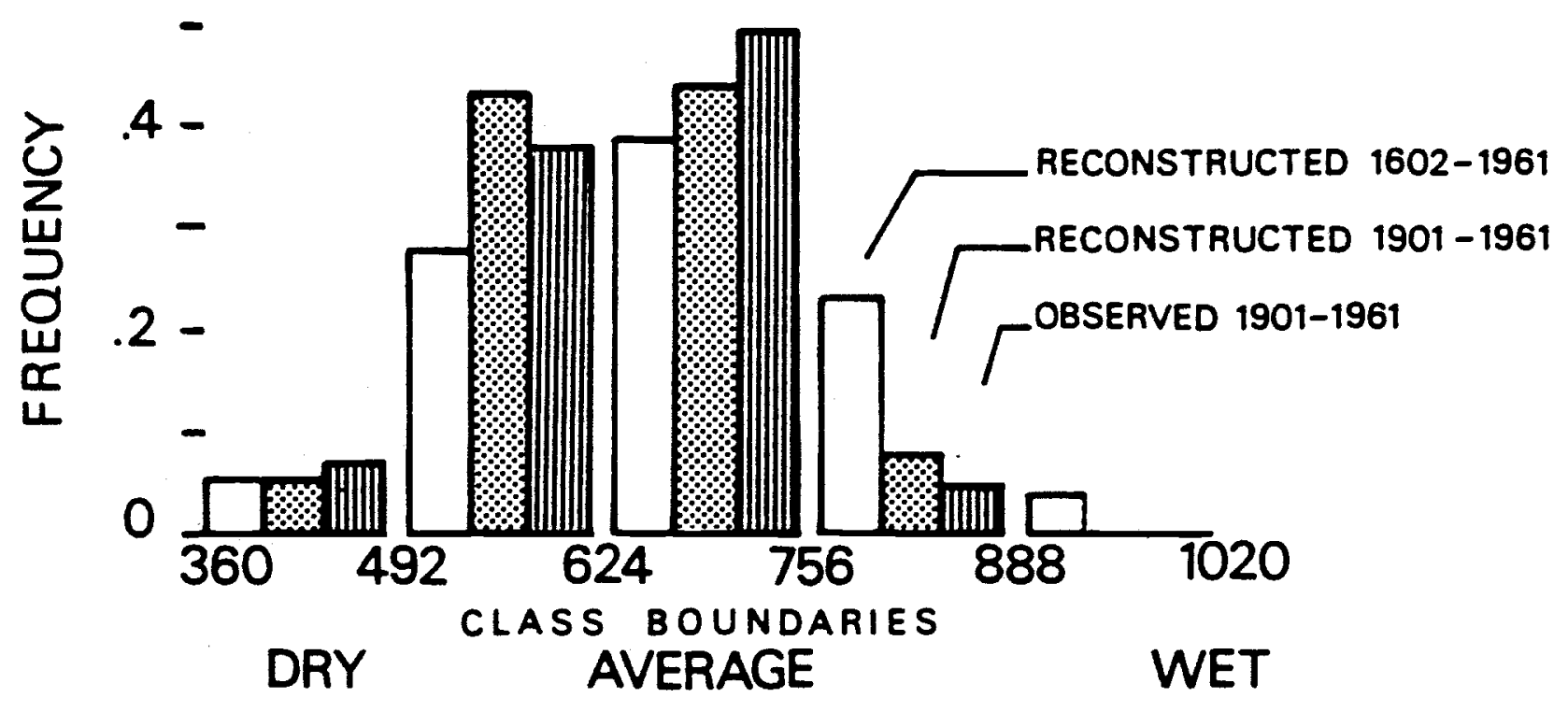

- REGION 3, INTERMOUNTAIN BASINS

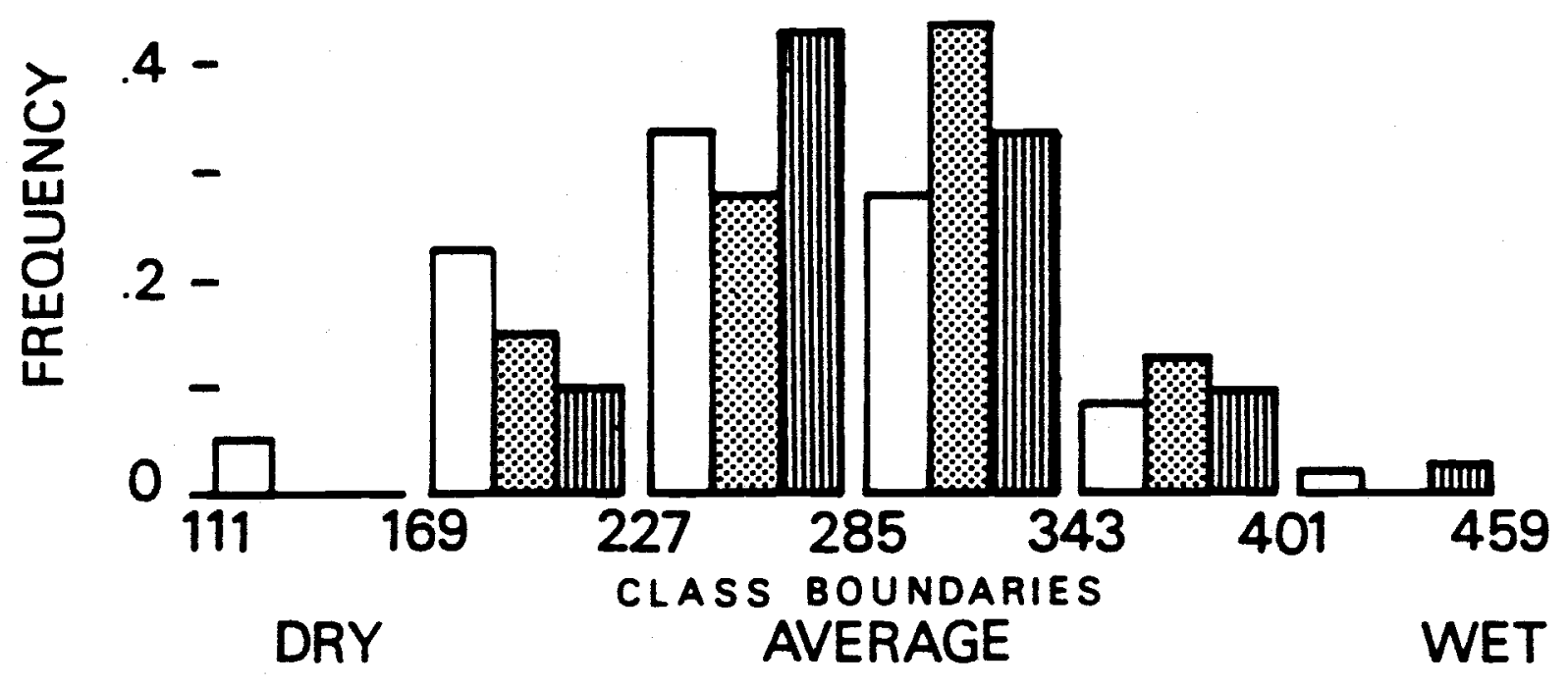

Figure 5. The frequencies of annual precipitation in several equal-sized classes expressed in millimeters for the six selected regions: (1) observed for 1901-1961, (2) reconstructed for 1901-1961 and adjusted to have comparable means and standard deviations, and (3) reconstructed for 1602-1961 using the same adjustments applied to the 1901-1961 reconstructions. Figure 5 is for Region 1, Columbia Basin, and Region 3, Intermountain Basins. 

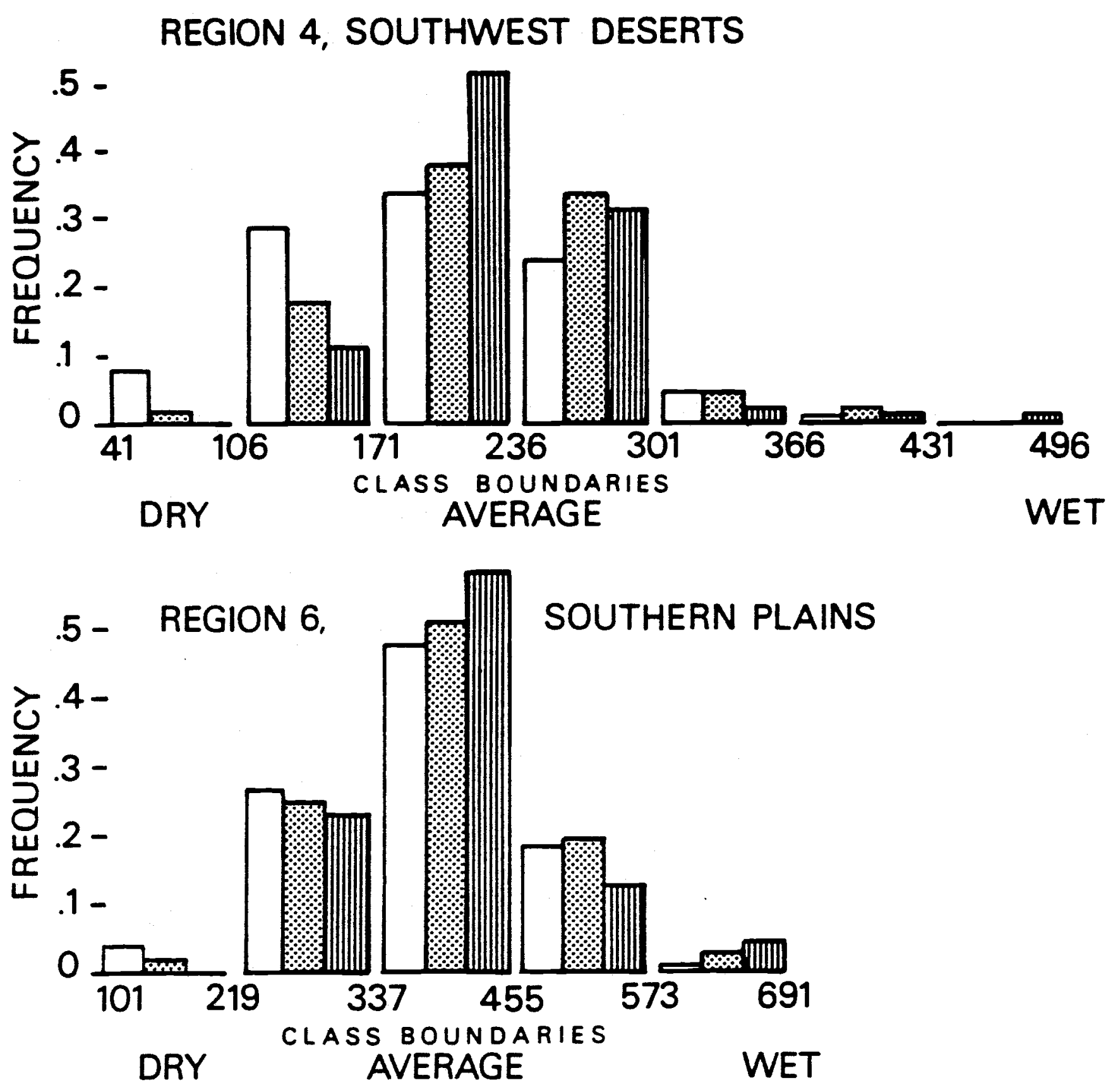

Figure 6. Same as Fig. 5, but for Region 4, Southwest Deserts, and Region 6, Southern Plains. 


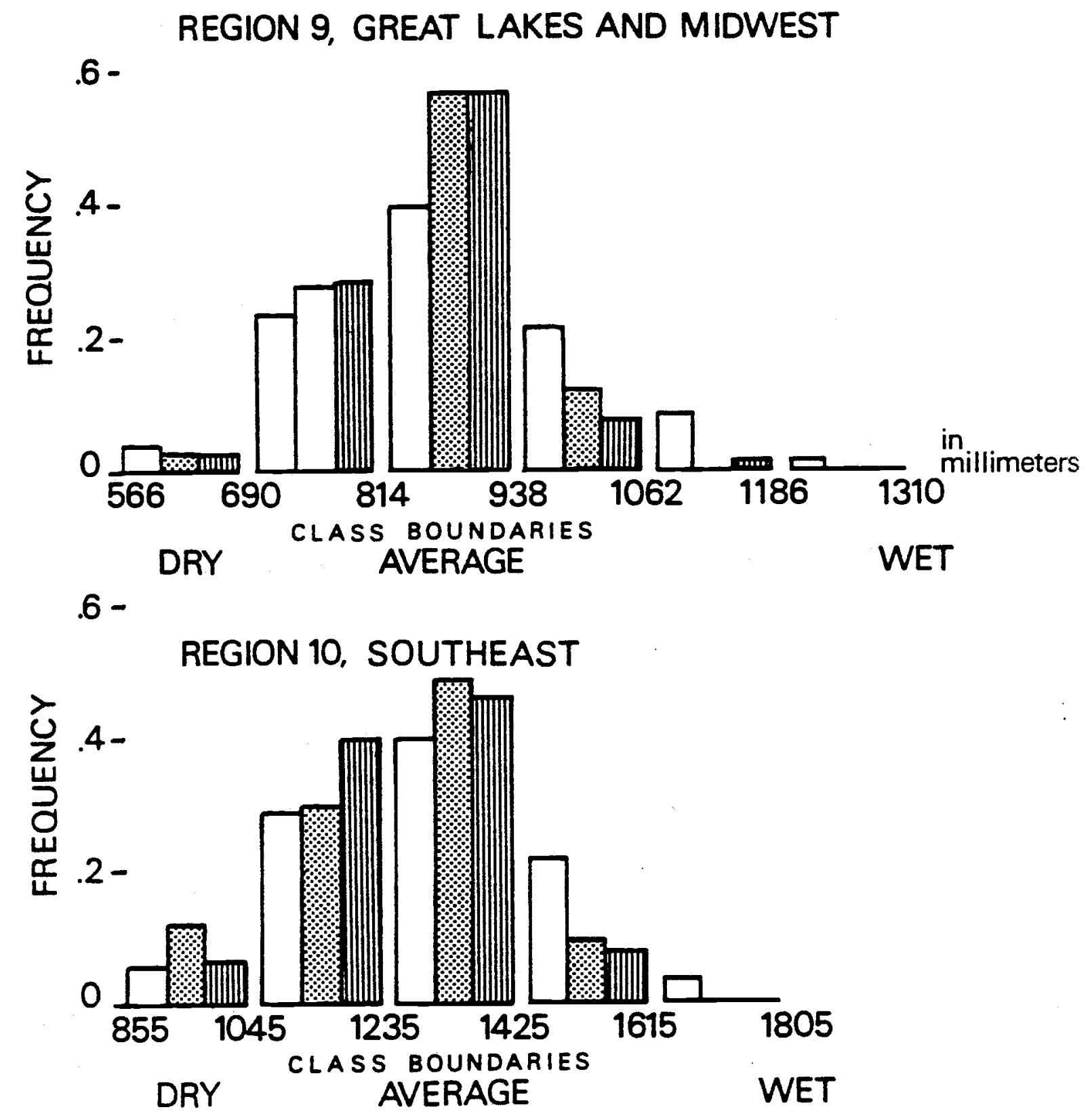

Figure 7. Same as Fig. 5, but for Region 9, Great Lakes and Midwest, and Region 10, Southeast. 
TABLE I. Summary of Verification Test Results for Final Reconstructions Used in This Analysis

Test Independent Period ${ }^{l}$ Calibration Period $^{2}$

Correlation coefficient, \% 27 96

Correlation on first differences, \% 23 94

Sign agreement, \% 18 84

Sign agreement on first differences, \% 7 74

Product means, \% 18

Total tests passed, \%

19

88

Reduction of error greater than zero, \%

52

98

Chi-square value for pooled data ${ }^{3}$

176

1,670

${ }^{1}$ All available data prior to 1901.

${ }^{2} 1901-1961$.

$395 \%$ critical level $=83$. 
TABLE II. Calibration and Verification Statistics for Two Models Used to Reconstruct Annual Precipitation

\begin{tabular}{lcc} 
& $\begin{array}{c}\text { Developmental } \\
\text { Model }\end{array}$ & $\begin{array}{c}\text { Final } \\
\text { Model }\end{array}$ \\
\hline $\begin{array}{l}\text { Dependent Data (1901-1961) } \\
\text { Variance Calibrated, \% }\end{array}$ & 50 \\
\\
Independent Data (Earlier than 1901) & & 19 \\
Verification Tests Significant, \% & 15 & 52 \\
Reduction of Error Greater than Zero, \% & 37 & .12 \\
Pooled Positive Reduction of Error & .10 & 176 \\
Chi-square &
\end{tabular}

${ }^{1}$ Negative values set to zero and values weighted for sample size before pooling.

$295 \%$ critical level $=83$. 
TABLE III. Station Names and Numbers Included in Each Region of Precipitation Grid

REGION

Name
Columbia Basin
1
Intermountain Basins

Southwest Deserts

4

Southem Plains

Great Lakes and Midwest

Southeast

10

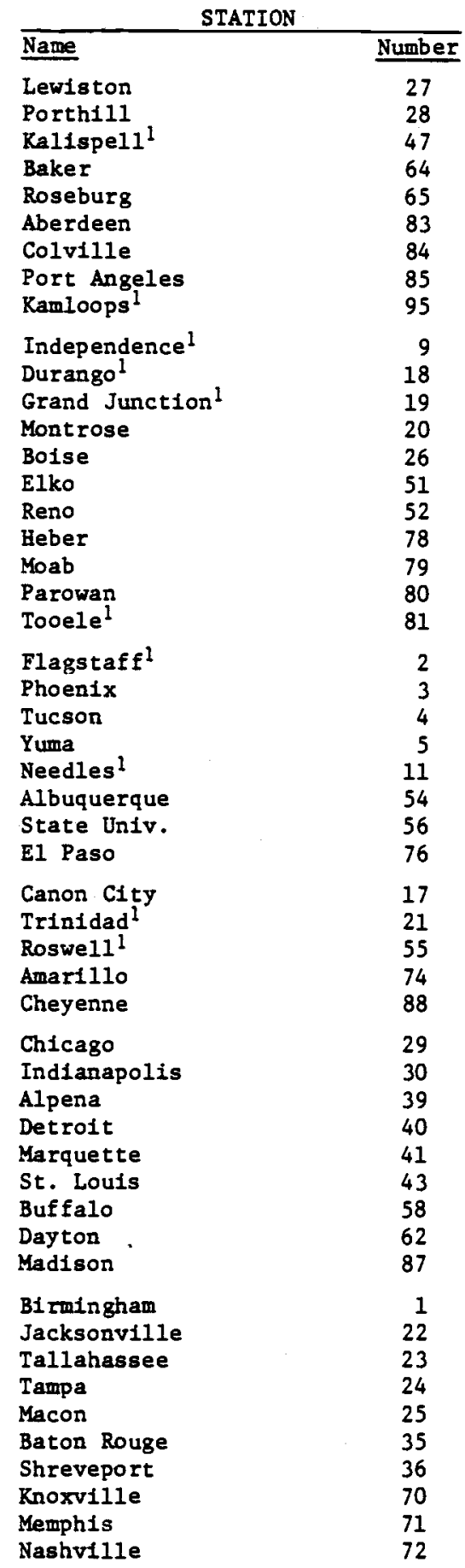

\footnotetext{
${ }^{1}$ Denotes station not verified $(<7$ years of independent data).
} 
TABLE IV. Percent Variance Agreement and Selected Verification Statistics for the Reconstructed and Actual Measurements of Annual Precipitation Tabulated by Region

1. Region Name

2. Region Number

3. Model ${ }^{1}$

\section{Calibration $\mathbf{r}^{2}$}

4. Individual Stations ${ }^{2}$

Regional Reconstructions

6. Regional Reconstructions ${ }^{3}$ Filtered

7. $\frac{\text { Row } 6-\text { Row } 4}{\text { Row } 4} \times 100$

Verification Statistics Individual Stations

8. \% Statistics Significant

9. Avg. $r^{2} \times 100$

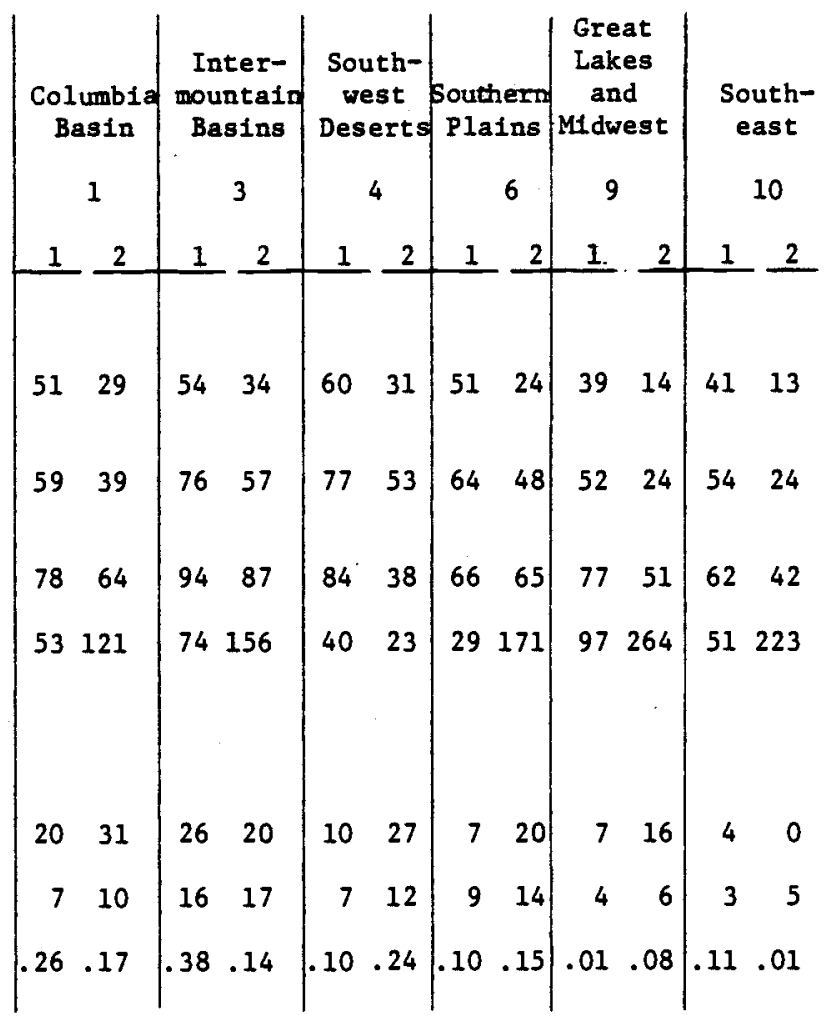

${ }^{1}$ Developmental model is number 1 , final model is number 2.

${ }^{2}$ Correlations squared for individual stations averaged.

${ }^{3}$ Individual station reconstructions and actual data averaged by region and the correlations between the two squared before and after filtering. 
TABLE V.a. Reconstructed Yearly Precipitation Expressed as Frequencies of Occurrences Within Five Equal-sized Classes for 1602-1961, $1901-1961,1901-1930$, and 1931-1960

Upper and Lower Class Boundaries in Millimeters

$888-1020$

$756-888$

$624-756$

$492-624$

$360-492$
Region 1: The Columbia Basin

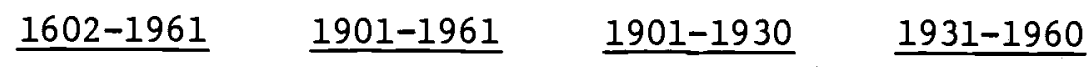

.04

.00

.00

.00

.23

.08

.06

.10

.39

.44

.30

.57

.28

.43

.56

.30

.05

.05

.07

TABLE V.b. Reconstructed Yearly Precipitation Expressed as Frequencies of Occurrences Within Five Equal-sized Classes for 1602-1961, $1901-1961,1901-1930$, and 1931-1960

Upper and Lower

Region 3: Intermountain Basins

Class Boundaries

in Millimeters

$$
\underline{1602-1961} \underline{1901-1961} \underline{1901-1930} \quad \underline{1931-1960}
$$

$401-459$

.02

.00

.00

.00

343-401

.09

.13

.17

.10

285-343

.28

.44

.53

.37

227-285

.34

.28

.27

.30

$169-227$

.23

.15

.03

.23

111-169

.05

.00

.00

.00 
TABLE V.c. Reconstructed Yearly Precipitation Expressed as Frequencies of Occurrences Within Six Equal-sized Classes for 1602-1961, $1901-1961,1901-1930$, and 1931-1960

Upper and Lower

Region 4: Southwest Deserts

Class Boundaries

$\begin{array}{ccccc}\text { in Millimeters } & \frac{1602-1961}{366-431} & \frac{1901-1961}{19} & & \frac{1901-1930}{1931-1960} \\ 301-366 & .01 & .03 & .03 & \frac{1931}{.03} \\ 236-301 & .05 & .05 & .10 & .00 \\ 171-236 & .24 & .34 & .30 & .40 \\ 106-171 & .34 & .38 & .47 & .27 \\ 41-106 & .29 & .18 & .07 & .30 \\ & .08 & .02 & .03 & .00\end{array}$

TABLE V.d. Reconstructed Yearly Precipitation Expressed as Frequencies of Occurrences Within Six Equal-sized Classes for 1602-1961, 1901-1961, 1901-1930, and 1931-1960

Upper and Lower

Region 6: Southern Plains

Class Boundaries

in Millimeters

$\underline{1602-1961}$

$\underline{1901-1961}$

$\underline{1901-1930}$

$\underline{1931-1960}$

573-691

.01

.03

.03

.03

455-573

.19

.20

.20

.16

$337-455$

.48

.51

.54

.50

219-337

.27

.25

.23

.26

101-219

.04

.02

.00

.03 
TABLE V.e. Reconstructed Yearly Precipitation Expressed as Frequencies of Occurrences Within Six Equal-sized Classes for 1602-1961, $1901-1961,1901-1930$, and 1931-1960

Upper and Lower

Class Boundaries

in Millimeters

Region 9: Great Lakes and Midwest

$1186-1310$

$1062-1186$

$938-1062$

$814-938$

$690-814$

$566-690$
1602-1961

.02

.09

.22

.40

.24

.04 $\underline{1901-1961}$

.00

.00

.12

.57

.28

.03

\section{$\underline{1901-1930 \quad \underline{1931-1960}}$}

.00

.00

$.00 \quad .00$

$.16 \quad .07$

$.60 \quad .54$

$.20 \quad .37$

$.03 \quad .03$

TABLE V.f. Reconstructed Yearly Precipitation Expressed as Frequencies of Occurrences Within Six Equal-sized Classes for 1602-1961, $1901-1961,1901-1930$, and 1931-1960

Upper and Lower Class Boundaries in Millimeters

$1615-1805$

$1425-1615$

$1235-1425$

$1045-1235$

855-1045
Region 10: Southeast

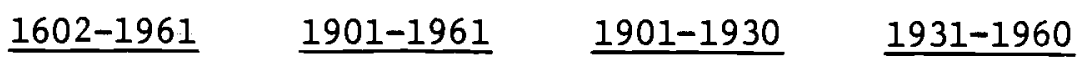

.04

.00

.00

.00

.22

.10

.13

.03

.40

.49

.33

.67

.29

.30

.33

.27

.06

.12

.20

.03 
TABLE VI. The Reconstructed Means and Standard Deviations ${ }^{l}$ for Three Different Control Intervals and 1602-1961, and the Highest and Lowest Values for 25-Year Intervals, Expressed as a Departure from the Values of the Three Control Intervals

Control Intervals 1901-1961

$1901-1930$

$1931-1960$

Departure for 1602-1961 from 1901-61

from $1901-30$ from $1931-60$

Highest 25-Year Value First Year of Interval departure from 1901-61 departure from 1901-30 departure from 1931-60

Lowest 25-Year Value First Year of Interval departure from 1901-61 departure from 1901-30 departure from 1931-60

\begin{tabular}{|c|c|c|c|c|c|c|c|c|c|c|c|}
\hline \multirow{2}{*}{\multicolumn{2}{|c|}{$\begin{array}{l}\text { Region } 1 \\
\text { Mean S.D. }\end{array}$}} & \multirow{2}{*}{\multicolumn{2}{|c|}{$\frac{\text { Region } 3}{\text { Mean S.D. }}$}} & \multirow{2}{*}{\multicolumn{2}{|c|}{$\begin{array}{l}\text { Region } 4 \\
\text { Mean S.D. }\end{array}$}} & \multirow{2}{*}{\multicolumn{2}{|c|}{$\begin{array}{l}\text { Region } 6 \\
\text { Mean S.D. }\end{array}$}} & \multirow{2}{*}{\multicolumn{2}{|c|}{$\begin{array}{l}\text { Region } 9 \\
\text { Mean S.D. }\end{array}$}} & \multirow{2}{*}{\multicolumn{2}{|c|}{$\begin{array}{l}\text { Region } 10 \\
\text { Mean S.D. }\end{array}$}} \\
\hline & & & & & & & & & & & \\
\hline 631 & 87 & 287 & 49 & 227 & 59 & 394 & 84 & 845 & 79 & 1250 & 140 \\
\hline 612 & 89 & 301 & 42 & 237 & 60 & 403 & 81 & 854 & 84 & 1224 & 160 \\
\hline 650 & 83 & 275 & 53 & 217 & 59 & 382 & 86 & 835 & 75 & 1268 & 111 \\
\hline $\begin{array}{l}55 \\
75 \\
36\end{array}$ & $\begin{array}{l}36 \\
34 \\
40\end{array}$ & $\begin{array}{l}-21 \\
-35 \\
-9\end{array}$ & $\begin{array}{r}11 \\
19 \\
8\end{array}$ & $\begin{array}{l}-29 \\
-39 \\
-19\end{array}$ & $\begin{array}{l}6 \\
5 \\
6\end{array}$ & $\begin{array}{r}-13 \\
-22 \\
-1\end{array}$ & $\begin{array}{l}6 \\
8 \\
3\end{array}$ & $\begin{array}{l}45 \\
37 \\
56\end{array}$ & $\begin{array}{l}48 \\
43 \\
52\end{array}$ & $\begin{array}{l}61 \\
87 \\
42\end{array}$ & $\begin{array}{l}33 \\
14 \\
63\end{array}$ \\
\hline $\begin{array}{r}1626 \\
210 \\
230 \\
191\end{array}$ & $\begin{array}{r}1676 \\
57 \\
55 \\
60\end{array}$ & $\begin{array}{r}1602 \\
49 \\
35 \\
61\end{array}$ & $\begin{array}{r}1602 \\
29 \\
37 \\
26\end{array}$ & $\begin{array}{r}1826 \\
-5 \\
-15 \\
5\end{array}$ & $\begin{array}{r}1726 \\
-\quad 15 \\
14 \\
16\end{array}$ & $\begin{array}{r}1626 \\
36 \\
26 \\
47\end{array}$ & $\begin{array}{r}1651 \\
17 \\
20 \\
14\end{array}$ & $\begin{array}{r}1626 \\
215 \\
206 \\
226\end{array}$ & $\begin{array}{r}1826 \\
67 \\
62 \\
71\end{array}$ & $\begin{array}{r}1626 \\
323 \\
350 \\
305\end{array}$ & $\begin{array}{r}1651 \\
39 \\
20 \\
69\end{array}$ \\
\hline $\begin{array}{r}1676 \\
-20 \\
0 \\
-39\end{array}$ & $\begin{array}{r}1651 \\
3 \\
1 \\
6\end{array}$ & $\begin{array}{r}1651 \\
-54 \\
-68 \\
-41\end{array}$ & $\begin{array}{r}1626 \\
-14 \\
-6 \\
-17\end{array}$ & $\begin{array}{r}1876 \\
-56 \\
-66 \\
-47\end{array}$ & $\begin{array}{r}1626 \\
-16 \\
-17 \\
-15\end{array}$ & $\begin{array}{r}1851 \\
-63 \\
-72 \\
-51\end{array}$ & $\begin{array}{r}1751 \\
-14 \\
-12 \\
-17\end{array}$ & $\begin{array}{r}1851 \\
-34 \\
-42 \\
-23\end{array}$ & $\begin{array}{r}1876 \\
5 \\
1 \\
10\end{array}$ & $\begin{array}{r}1851 \\
-63 \\
-37 \\
-82\end{array}$ & $\begin{array}{r}1751 \\
-21 \\
-41 \\
8\end{array}$ \\
\hline
\end{tabular}

\footnotetext{
${ }^{1}$ Expressed as of precipitation.
} 
REFERENCES

Barry, Roger; Fritts, Harold; Imbrie, John; Mitchell, J. Murray; and Savin, Samuel M. 1979. Paleoclimatic Research: Status and Opportunities. (Alan D. Hecht, ed.) Quaternary Research 12(1):6-17.

Blasing, T. J. 1978. Time Series and Multivariate Analysis in Paleoclimatology. In "Time Series and Ecological Processes" (H. H. Shugart, Jr., ed.),

pP. 213-228. SIAM-SIMS Conference Series, No. 5. Society for Industrial and Applied Mathematics, Philadelphia, Pennsylvania. 328 pp.

Bryson, R. A. and Hare, F. K. 1974. World Survey of Climatology, Vol. 11. Climates of North America. (H. E. Landsberg, ed.) Elsevier Scientific Publishing Company, New York. 420 pp.

DeWitt, E. 1978. Temperature and Precipitation Station Selection. Technical Note \#3, Laboratory of Tree-Ring Research, University of Arizona, Tucson.

Fritts, H. C. 1965. Tree-Ring Evidence for Climatic Changes in Western North America. Monthly Weather Review 93(7):421-443.

Fritts, H. C. 1974. Relationships of Ring Widths in Arid-Site Conifers to Variations in Monthly Temperature and Precipitation. Ecol. Monogr. $44(4): 411-440$.

Fritts, H. C. 1976. Tree Rings and Climate. Academic Press, London. 567 pp.

Fritts, H. C.; Blasing, T. J.; Hayden, B. P.; and Kutzbach, J. E. 1971. Multivariate Techniques for Specifying Tree-Growth and Climate Relationships and for Reconstructing Anomalies in Paleoclimate. Quatermamy Resecrch $10(5): 845-864$.

Fritts, H. C., Lofgren, G. R., and Gordon, G. A. 1979. Variations in Climate Since 1602 as Reconstructed frow Tree Rings. Quatermary Research 12(1):18-46.

Fritts, H. C. and Shatz, D. J. 1975. Selecting and Characterizing Tree-Ring Chronologies for Dendroclimatic Analysis. Tree-Ring Bull. 35:31-40.

Kennedy, E. In preparation. Sources of Inaccuracy in Verification Data for Climatic Reconstruction. Technical Note \#16, Laboratory of Tree-RIng Research, Untversity of Arizona, Tucson.

Kutzbach, J. E. and Guetter, P. J. In press. On the Design of Paleoclimatic Data Networks for Estimating Large-Scale Circulation Patterns. Quatemary Research.

LaMarche, V. C., Jr. 1974. Paleoclimatic Inferences from Long Tree-RIng Records. Science 183:1043-1048.

LaMarche, v. C., Jr. 1978. Tree-RIng Evidence of Past Climatic Variability. Nature 276:334-338.

LaMarche, V. C., Jr., and Harlan, T. P. 1973. Accuracy of Tree-Ring Dating of Bristlecone Pine for Calibration of the Radiocarbon Time Scale. J. Geophys. Res. $78(36): 8849-8858$. 
Lorenz, E. N. 1956. Empirical Orthogonal Functions and Statistical Weather Prediction. M. I. T. Stat. Forecasting Proj. Sci. Rep. 1, Contract No. AF 19(604)-1566.

Palmer, Wayne C. 1965. Meteorological Drought. U. S. Department of Commerce Research Paper No. 45.58 pp.

Panofsky, H. A. and Brier, G. W. 1965. Some Applications of Statistics to Meteorology. Pennsylvania State Univ., University Park.

Potter, G. 1979. Past C11mate Reconstruction: A Tool for Assessing Site Suitability. Lawrence Livermore Laboratory, UCID-18118. Livermore, California. $18 \mathrm{pp}$.

Stockton, C. W. and Meko, D. M. 1975. A Long-Term History of Drought Occurrence in Western United States as Inferred from Tree Rings. Weatherwise 28(6): 244-249.

Webb, T. and Clark, D. R. 1977. Calibrating Mlcropaleontological Data in Climatic Terms: A Critical Review. Annals of the New York Academy of Sciences 288: 93-118. 


\section{APPENDIX IA \\ REgIONAL TIME SERIES ANALYSIS PROGRAY PACKAGE}

\section{INTRODUCTION}

The ajor purpose of the climate Reconstruetion 3 project under the direction of $\mathrm{H}$. C. Fritts at the Laboratory of Tree-Ring Research is to use climatic data to callbrate the tree-ring data to produce seasonal and annual reconstructions of climate back to the year 1602. Climatic reconstructions consist of a climatic estimate for each year reconstructed for each station in the grid used.

In order to analyze larger geographlcal areas of the united states and canada, the reconstructions may be "regionalized," or averaged over soecified regions of the grid to produce time series for that region. The tasks of averaging and analyzing the averaged values are the functions of the programs described in this document. Progran CCLTIM denormalizes and averages the individual station reconstructed estimates; Program CCROSS calculates 
statistics for unfiltered and lowmass filtered periods for actual and reconstructed values and also calculates adjusted statistics for comparisons between actual data and reconstructions; Program CPROB examines the frequency domains of actual and reconstructed values and compares the statistics of past periods with periods within the present century.

These programs are written In FORTRAN Extended Version 4 for use on the CYBER 175 computer, but may be used and maintalned through disk storage on the CYBER or DEC-10 computer. Each program ay be used alone or in combination Wth the other programs. 
CCLTIM

\section{General Deserlotion}

Progran CCLTIM extracts time series files from clinatic reconstruction or actual data flies. CCLTIM reads the following flies:

1. Seasonallzed climatic reconstructions or seasonalized actual data as output by PRINCY forogran package which seasonallzes data and extracts princlpal components),

2. reconstruction statistics including standard deviations of residuals and callorated varlance by station,

3. Station Identification numbers,

4. station means and standard deviations for the callibration period, and

5. grid point numbers for all regions and all grids.

From these flies, time serles are extracted and written on an output file. Lines of header are written and regionalized values follow. Standard errors, if desired, follow immediately in the same format (fig. 1; see Appendix 1B1. In addition, another file is written contalning the wean calibrated variances for the callibration perlod for each region averaged from intividual station 
calibrated varlances read from flle 2 (flg. 2 ). See

Section II for the exact formats of these files.

\title{
Proceduce of Extraetiog Iime Serles
}

\author{
NOTE
}

\begin{abstract}
CCLTIM is capabie of extracting individual station time series and this option will be included in our description even though the option has, to date, not been tested for the most recent version of the program. Though it does not realiy belong in a "regionalizing" effort, it is concelvable that this option will prove useful in the future.
\end{abstract}

CCLTIM begins by reading the entire cllmatle reconstruction fle or actual data and storing them; specifled beginning and ending years are located in the array. sums, sums of squares, sums of variances, variances, and standard errors for each year are calculated if standard errors are pequested. For Individual grid point time serles, standard errors ay be calculated, but yearly standard errors will be Identical to one another and meaningless.

\section{Equations}

Table I (p. 1-22, Appendix 1B) is a description of the equations used for the various conditions of data. Equations marked with an at symol (a) may be performed on Individual grid point series. 
Throughout this section, actual variable names are used in equations to avold confusion with other varlables. The more routine calculations are usually performed in subroutines and standard notation wlll be used to represent these operations here, but many equations are quite program-soecific and are Identlfied as they appear in the code for the benefit of the programmer who must locate them In the future.

Basic units used for data and standard errors are degrees Farenhelt for temperature and inches for precipitation, but conversion to degrees Centigrade or millimeters may be done as in Equations 1 and 2. (See p. 1-18, Apsendix 1B.)

In addition, an average of the percent variance calibrated for each region is calculated by averaging individual station percent variances over the number of grid points. 
CCROSS

\section{General Resefletion}

Program CCROSS reads the actual and reconstructed time series files and average callorated variance file output from Program CCLTIM. It then calculates for each region the means and standard deviations of actual data and reconstructions for several time periods and writes a summary table (FIg. 3).

1. means, standard deviations, and percent variances are calculated for unfiltered and low-pass flltered actual data and reconstructions for the "common periadn or a set of years common to both the actual and reconstructed series. If the common period is not soecified by the user, it is defined as the calibration period. The first year of the common or calibration periof is always 1901 whlle the last year varies from 1960 to 1963 , depending on the model and season used for reconstruction;

2. means and standaro deviations are calculated for unfiltered reconstructions for the perlods 1602-1900, and 1602 through the last year of the callibration period; 
3. means and standard deviations are calculated for unflitered actual data for the period 1901-1970;

4. comparisons between the actual means and standard deviations and the precalibration perlod (160?-1900) and full perlod (1602-196-) are made using a correction ratio (the ratio of the actual common perlod stantard deviation to the reconstructed common period standard deviations. This ratio is multiplied by the reconstruction oerlod standard deviation to "inflate" the varlance in the reconstruction and thus allow comparisons between the past reconstructed estimates and the more variable actual calibration period series isee "Comparative statistics" section below).

\section{S5atLs_Lss}

General Statistles. Means and standard deviations are calculated for the folloulng data sets:

1. actual common period, (1901-196-1, unflitered

2. reconstruction common perlod, unflitered

3. actual common period, low-pass filtered

4. reconstruction common period, low-pass filtered

5. reconstruction precalibration periof (1602-1900), unfiltered 
6. reconstruction full perlod (1602-196-), unfiltered

7. actual full period (1901-1970), unfiltered

Means are calculated as the sum of the data values divided by the number of years in the time period. Standard deviations are calculated as in Equation 3.

Four different percent variances are calculated:

1. percent varlance of the reconstruction due to low-pass filtering (RECPCT) as in Equation 4 ,

2. mean percent varlances (VARIND) for a reglon for the calibration period obtained by a simple average of station percent variances. The station percent variance values are read from the calibration statistics file.

3. percent variances between actual and reconstructed unfiltered series for the control period (PVABC) calculated as in Equation 5 and expressed as percentages.

4. percent variances between actual and reconstructed Iow-pass filtered serles for the control period (PVABCL) as in Equation 5 and expressed as percentages.

For further explanation of Equation 5 , see Davis, $s$. C., 1973. Statlstles 3nd Data Analysis lo Geology, John wiley and Sons, Inc., New York. 
comparatlye statlstles. The following comoarative statistics are calculateds

1. correction ratio (CRATIO) of the actual standard deviations for the common period (SOBC) to the reconstructed standard deviation of the same period (SDAC) as in Equation 6,

2. difference (AVDIFF) between unfiltered reconstruction mean, 1602-1900 (A2BAR) and the actual mean, 1901-1970 (BBAR) as in Equation 7 ,

3. ratio (PCTOIF) of diff (AVOIFF) to actual mean (BSAR), expressed as a percentage (5q. 8),

4. adjusted standard deviation for precalibration period, 1602-1900 (ADJSDR), derived from the unfiltered reconstruction standard deviation of that oeriod (SDA2) as In Equation 9 ,

5. adjusted standard devlation for full perlof, 1602-196(ADJSDT), derived from the unflltered standard deviation of that perlod (SOA) as In Equation 10 ,

6. difference (SOD) of adjusted standard deviation, 1602-1900 (ADJSDR), minus the actual full perlod standard devlation, 1602-196- (SOBI, as in Equation 11,

7. ratio (PCTSDD) of SDD to standard deviation of actual full perlod, 1602-196- (SDB), expressed as a percentage (Eq. 12). 


$$
1-10
$$

scaling Easter. In addition, scaling factors for low-dass filtered standard errors (SCALE) are calculated for each region as the ratio of the lom-pass filtered, reconstruction control period standard deviation (SOACL) to the unfiltered reconstruction control period standard deviation ISOAC as in Equation 13). These scaling factors are multiplied by the standard errors when low -pass filtered reconstructed time series are to be plotted by programs CCPLOT and LPPLOT.

QuIpus. Output consists of a table containing all the above statistics (Fig. 3) except the scaling factors which are output on a separate file (Fig. 4 ). 
CPROS

\section{General Reserletion}

Program CPROB examines two time serles, one actual and one reconstructed, and compares the frequencles of occurrences of class intervals in the calibration period and in the entire reconstruction period. The user is llowed to select "control periods" or subsets of the callbration oeriod, in which frequencies of actual and reconstructed vaues are compared, theoretical probablities are calculated for the Intervals, and a chl square test is performed. The user is also allowed to select a number of mreconstruction periods, or subsets of the entire reconstruction period, to comoare with the reconstruction control perlod frequencies. Interval size is determined by the program on the basis of the minimum interval size and the total number of classes specified by the user and the means and distributions of the data belng analyzed. Isee "Selection of Class intervals" section later In this document.l

The reconstructed estimates to be analyzed are radjustedn using the actual and reconstruction means and standard deviations for the calibration period. The variance of a reconstruction during the calibration perlod has been forced to be saller than the variance of actual data for the same period. In order to make a valid comparison, the entire reconstruction time serles must be adjusted for the change In variance as in Equation 14. If precioitation is being 
analyzed, all negative values resulting fron this adjustment are reset to zero.

CPROB produces four tables (FIgs. 5-8) for each region or set and each control perlod. The contents of each table are descrlbed in the next section.

\section{Quseut and statistles}

Iable I=ceonfol peciod Ereguencles and Statisties. Table I of CPROB output (Fig. 5 ) contains interval counts and frequencies of actual and reconstruction values for the particular control perlod, differences between reconstruction and actual frequencles, and the following theoretical probabilities:

1. probability that a climatic measurement in any year $(x)$ wII fall within the interval, i.e., it will be greater than the lower llite of the class (LL) and equal to or less than the upper class limit (UL),

2. probability that $x$ will be equal to or less than the lower class IInit, and

3. probablitity that $x$ will be greater than the upper class Iinit.

These orobabllities are determined by finding the $z$-value or normal curve equivalent of the upper and lower class $11 \mathrm{mits}$ using the reconstruction wean and standard deviation for the 
control period to normallze the limits, as in Equation 15.

NOTE

Though calculation is done progressively from minimum to maximum, the table is printed out in reverse order, from the maximum as Class 1 to the ninimum as Class $n$ (up to 20 ).

Control perlod statistics also appear in Table I. In general, basic statistics are calculated as in Equations 16 , 17, and 18. In addition, control period minima and maxima are located and the differences between al i coconstruction and actual statistics are calculated. The last items in Table I are the results of the chl square test, which are discussed in the next section.

\section{Iable II =centingency Iable and chl square Results IElo.}

21. Printing of Table II is optional-the oniy item that appears here and not in Table I is the contingency table for the actual and reconstruction counts.

Chi square is calculated as in Equation 19, and degrees of preedon are calculated as in Equation 20. If a row or column total is zeros that category is conbined witt the adjacent category and the degrees of freedon are reduced accordingly (Eq. 20) for the particular cell. For degrees of freedom greater than 30 , the critical chi square value is approxinated as in Equation 21. 
When chi square is significant, the coefficient of contingency which measures the degree of rolatedness of the two series, is calculated as in Equation 22.

NOTE

The classes used for the chi square test are arbitrary and net equally ergbable, and samole slzes are often too small to make statenents about significance, so the researcher should use these chi square results cautlousiy.

IabLe III ==Regenstruetlon gefled Eregueneles lEles IL. Table III, llke Table I, presents the class frequencies and theoretical probablilties for a control period as the first lines in the table, and proceeds to list the frequencies of the reconstruction periods along with the differences between the recon period and control period frequencies as nell as the theoretical probabilities of the same class intervals determined by the same process as the control period probabilities, but now reconstruction pepiod statistics are used to normalize the class bounds as in Equation 23. Up to 50 reconstruction periods may be analyzed in this fashion.

Iable IV $==$ Recenstructien gerled Staflstles IElas Bl. Table IV lists the reconstruction statistles of the control period (from rable I), and follows these with the statistics of all the reconstruction perlods as well as the differences between the reconstruction perlod and control period 
statistics. All reconstruction perlod statistics and differences are also averaged, and the user should note that this average may be meaningless if uneaual or overlapping series are used.

Seleation of class Intecrals. Class intervals are selected by Program CPROB through a process of surveying all the data to be analyzed, determining means, maxima, and minima of a II periods, and adjusting the interval range so that no data ralue will be out of bounds.

In order to ensure comparability of the regional analyses, the user defines a "minimum interval sizen (RMININT), or the smallest interval to be allowed for a class le.g., a quarter-degree for temperature or a millineter for orecipltations. All classes will be multioles of the ninimum interval. The program reads the actual data and the adjusted reconstruction for all time periods and reans, mins, and maxes are calculated for each. For each region, the largest time period maximum and smallest time period minimum are selected.

In addition, a "grand mean" (GRANDMN) is calculated which is the mean of all perlod means for all regions. The minimum Interval size is nultiplled by half of the total number of specified classes, to obtain a value for the varlable RANGE. The value of RANGE is then tested against the absolute value of the largest departure of the max or min (SETMAXO) of each 
region from the GRANDMN. If SETMAXD for a region is greater than RANGE, the minimum interval (RMININT) is multiolied by a variable, MULT, which has the value of 2 and is increased by 1 for each additional time the product does not exced SETMAXD. When RANGE finally does exceed SETMAXD, RANGE is added to GRANDMN to yleld the Interval maximum (VMAX) and subtracted from GRANOMN to yield the interval minimum (VMIN). The boundaries of the intervals are then rounded off to the nearest tenth if VMaX is less than 100 or to the nearest unit if VMAX is greater than or equal to 100.

If precipitation is being analyzed, the progran checks to see if VMIN is positive or negative. If it is negative, it is reset to zero and rmax is adjusted proportionately. This scheme prevents the occurrence of a time series value falling out of the defined bounds exceot in the rare case when the boundary rounding causes one value to fall just outside the calculated limits. In such a case, the value is included in the nearest class and an error message is printed on the progran output, but usually the value is near enough to the boundary that the problem is negliaible. See Figure 5 for an example of a set of defined intervals. 
APPENDIX 1B

Equations, Tables, and Figures for

Regional Time Series Job Stream 


\section{EQUATIONS USED IN \\ REGIONAL TIME SERIES \\ PROGRAM PACKAGE}

\section{$\underline{\text { CCLTIM }}$}

1) Centigrade conversion: $C=5(F-32) / 9$

2) Millimeter conversion: $M=(25.4) I$

\section{CCROSS}

3) Standard deviations:

$$
s_{x}=\sqrt{\frac{n \Sigma(x)^{2}-(\Sigma x)^{2}}{n(n-1)}}
$$

4) Percent variance due to low-pass filter:

$$
\mathrm{RECPCT}=\frac{(\mathrm{SDACL})^{2}}{(\mathrm{SDAC})^{2}} * 100
$$

5) $I_{\mathrm{m}}=\frac{\mathrm{n} *(\Sigma \mathrm{AB})-\Sigma \mathrm{A} \Sigma \mathrm{B}}{2}$

$$
\sqrt{\left[n * \Sigma A^{2}-(\Sigma A)^{2}\right]\left[n * \Sigma B^{2}-(\Sigma B)^{2}\right]}
$$

$$
r_{m}=\frac{\operatorname{cov}_{A, B}}{s_{A} s_{B}}
$$

where

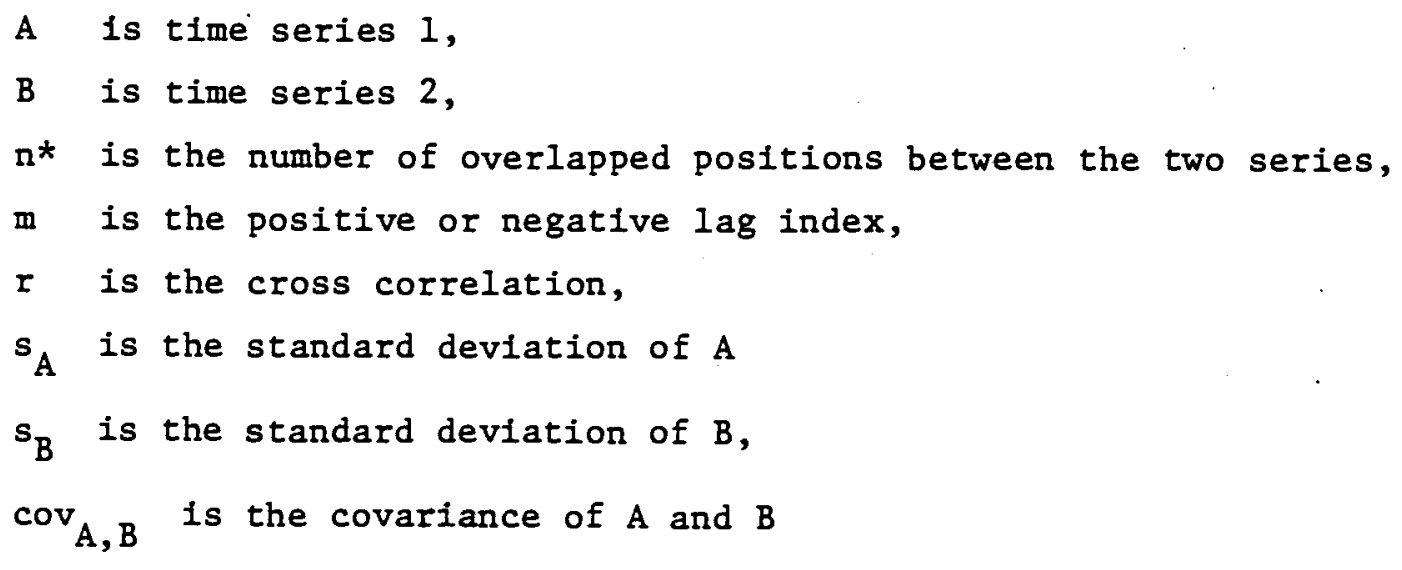

NOTE: In CCROSS, $r_{m}$ is multiplied by 100 to express percent variance calibrated. 
Equations 6 through 12 are comparative statistics.

\author{
6) $\quad$ CRATIO $=\underline{\text { SDBC }}$ \\ SDAC \\ 7) AVDIFF $=($ A2BAR - BBAR $) *$ CRATIO \\ 8) $\quad$ PCTDIF $=\frac{\text { AVDIFF }}{\text { BBAR }} * 100$ \\ 9) $\mathrm{ADJSDR}=\mathrm{SDA} 2 *$ CRATIO \\ 10) $\quad$ ADJSDT $=$ SDA * CRATIO \\ 11) $\mathrm{SDD}=\mathrm{ADJSDR}-\mathrm{SDB}$ \\ 12) $\mathrm{PCTSDD}=(\mathrm{SDD} / \mathrm{SDB}) * 100$ \\ 13) Scaling factor: \\ SCALE $=\underline{\text { SDACL }}$ \\ SDAC
}

$\underline{\text { CPROB }}$

14) Adjustment of denormalized values:

Denormalized reconstruction estimates are adjusted for comparison to actual data via the following equation:

$$
\hat{\mathrm{x}}_{I}=\left[\left(\mathrm{X}_{I}-\overline{\mathrm{x}}_{I}\right)\left(\frac{s_{a}}{s_{r}}\right)\right]+\overline{\mathrm{x}}_{a}
$$

where

$$
\begin{aligned}
& \hat{\mathrm{X}}_{I} \text { is the adjusted reconstruction estimate for year } i \text {, } \\
& \mathrm{x}_{I} \text { is the nonadjusted reconstruction estimate for year } i \text {, }
\end{aligned}
$$


$\bar{x}_{r}$ is the mean of nonadjusted reconstruction estimates for the calibration period, $s$ is the standard deviation of actual data for the calibration
period,

$s_{r}$ is the standard deviation of reconstruction estimates for the calibration period, and

$\bar{x}_{a}$ is the mean of actual data for the calibration period.

15) Normalization of control period class limits for probability calculation:

$$
\mathrm{UL}=((I * \text { RANGE })+\mathrm{VMINI})-\mathrm{RCPMN}
$$

RCPSD

where

$I$ is the interval number,

RCPMN is the reconstructed control period mean,

RCPSD is the reconstructed control period standard deviation,

$\mathrm{UL}$ is the normalized upper limit of the interval, and

VMINI is the minimum of the data range.

16) Mean: $\overline{\mathrm{X}}=\underline{\Sigma \mathrm{X}}$

n

17) Standard deviation: $s_{x}=\sqrt{\frac{n \Sigma(x)^{2}-(\Sigma x)^{2}}{n(n-1)}}$

18) First-order autocorrelation: $I_{1}=\Sigma\left(x_{i}-\bar{x}\right)\left(X_{i-1}-\bar{x}\right) / s_{x}^{2} n$

19) Chi square $\left(x^{2}\right): h_{\operatorname{mn}}=k_{m}\left(\frac{r_{n}}{\Sigma r}\right)$

$$
\text { and } x^{2}=\Sigma\left(\frac{\left(f_{m n}-h_{m n}\right)^{2}}{h_{m n}}\right)
$$

where

$f_{m n}$ is the count within a cell mn of the contingency table,

$I_{n}$ is the total count in row $n$,

$k_{m}$ is the total count in column $m$, and

$\sum \mathrm{I}$ is the grand total ( $\mathrm{r}_{\mathrm{n}}$ or $\left.\mathrm{k}_{\mathrm{m}}\right)$. 
20) Degrees of freedom: ndf $=(n n-1)(m m-1)$

where

nn is the number of nonzero rows, and

$\mathrm{mm}$ is the number of nonzero columns.

21) Critical chi square value approximation for degrees of freedom greater than 30:

$$
x_{\alpha}^{2}=\left(x_{\alpha}+\sqrt{2 n-1}\right)^{2}
$$

2

where

$x_{\alpha}^{2}$ is the critical value of chi square for the chosen significance
level or alpha $(\alpha)$,

$X_{\alpha}$ is the normal curve approximate ( $Z$-value) of the chosen level of significance ( 1.645 in $\mathrm{CPROB})$, and

$n$ is the number of degrees of freedom.

22) Coefficient of contingency: $\quad c=\sqrt{\frac{x^{2}}{x^{2}+\Sigma r}}$

23) Normalization of reconstruction period class limits for probability calculation:

$$
\mathrm{UL}=\frac{((\mathrm{I} * \text { RANGE })+\mathrm{VMINI})-\mathrm{RPMN}}{\mathrm{RPSD}}
$$

where

I, RANGE, and VMINI are the same as in Equation 15,

RPMN is the mean of the reconstruction period, and

RPSD is the standard deviation of the reconstruction period.

- E. DeWitt

March, 1979 


\begin{tabular}{|c|c|c|c|c|}
\hline Statist1c & $\begin{array}{c}\text { Recon. } \\
\text { Normalized } \\
\end{array}$ & $\begin{array}{c}\text { Actual } \\
\text { Normalized }\end{array}$ & $\begin{array}{c}\text { Recon. } \\
\text { Denormalized }\end{array}$ & $\begin{array}{c}\text { Actual } \\
\text { Nonnormalize }\end{array}$ \\
\hline$x($ norm $)=$ & -- & $(X(L I)-F M N(L I))$ & -- & -- \\
\hline & & $\operatorname{SDV}(L I)^{\complement}$ & & \\
\hline $\mathrm{XDN}=$ & $-\infty$ & $-\infty$ & $\begin{array}{c}(X(L L) * \operatorname{SDV}(L I)) \\
F M N(L I)\end{array}$ & $-\infty$ \\
\hline$X S=$ & --- & --- & $\Sigma \mathrm{XDN}$ & --- \\
\hline$X S Q=$ & $\Sigma(X(L L))^{2}$ & $\Sigma(X(L L))^{2}$ & $\Sigma \mathrm{XDN}^{2}$ & $\Sigma(\mathrm{X}(\mathrm{LL}))^{2}$ \\
\hline SPROD = & $\Sigma(\operatorname{SDR}(\mathrm{LI}))^{2}$ & -- & $\Sigma(\operatorname{SDR}(\mathrm{LI}) * \operatorname{SDV}(\mathrm{LI}))^{2}$ & $-\infty$ \\
\hline \multirow[t]{2}{*}{$S S D=$} & $\underline{X Q}-\left(\mathrm{NGP} * \mathrm{TS}^{2}\right)$ & $X S Q-\left(N G P * T S^{2}\right)$ & $\left.X S Q-\frac{X S^{2}}{N G P}\right)$ & \multirow{2}{*}{$\frac{X S Q-\left(N G P * \mathrm{IS}^{2}\right)}{\mathrm{NGP}-1}$} \\
\hline & $N G P-1$ & NGP-I & NGP-I & \\
\hline \multirow[t]{2}{*}{$S E=$} & SSD + $\frac{\text { SPROD }}{N G P}$ & \multirow{2}{*}{$\frac{S S D}{N G P}$} & SSD $+\frac{\text { SPROD }}{\text { NGP }}$ & \multirow{2}{*}{$\sqrt{\frac{S S D}{N G P}}$} \\
\hline & NGP & & NGP & \\
\hline \multirow[t]{2}{*}{$\mathrm{TS}=$} & $\underline{\Sigma}(L L)$ & \multirow{2}{*}{$\Sigma\left(\frac{X(L L)-F M N(L I)}{S D V(L I)}\right)$} & $\underline{\operatorname{XDN}}$ & \multirow{2}{*}{$\frac{\Sigma X(L L)}{N G P}$} \\
\hline & NGP & & NGP & \\
\hline
\end{tabular}

where

FMN is the calibration mean for a particular grid point,

LI is the array of grid point numbers included in the regional average,

LL is the location in the $X$ array of a particular station and year,

NGP is the number of grid points in a region,

SDV is the calibration standard deviation for a particular grid point,

SDR is the calibration standard deviation of the residuals for a particular grid point,

$\mathrm{SE} \quad$ is the standard error for year $\mathrm{m}$,

SPROD is the sum of squared or scaled standard deviations of residuals,

SSD is the variance for year m over NGP grid points,

TS is the averaged or individual time series value for year $\mathrm{m}$,

$X$ is the time series value read from input data file,

$\mathrm{XDN}$ is a denormalized data value calculated for all years and grid points desirec

XS is the sum of denormalized values for year m over NGP grid points, and

XSQ is the sum of normalized, nonnormalized, or denormalized values for year w over NGP grid points.

@Calculation is made for individual station values as well as for averaged values. 

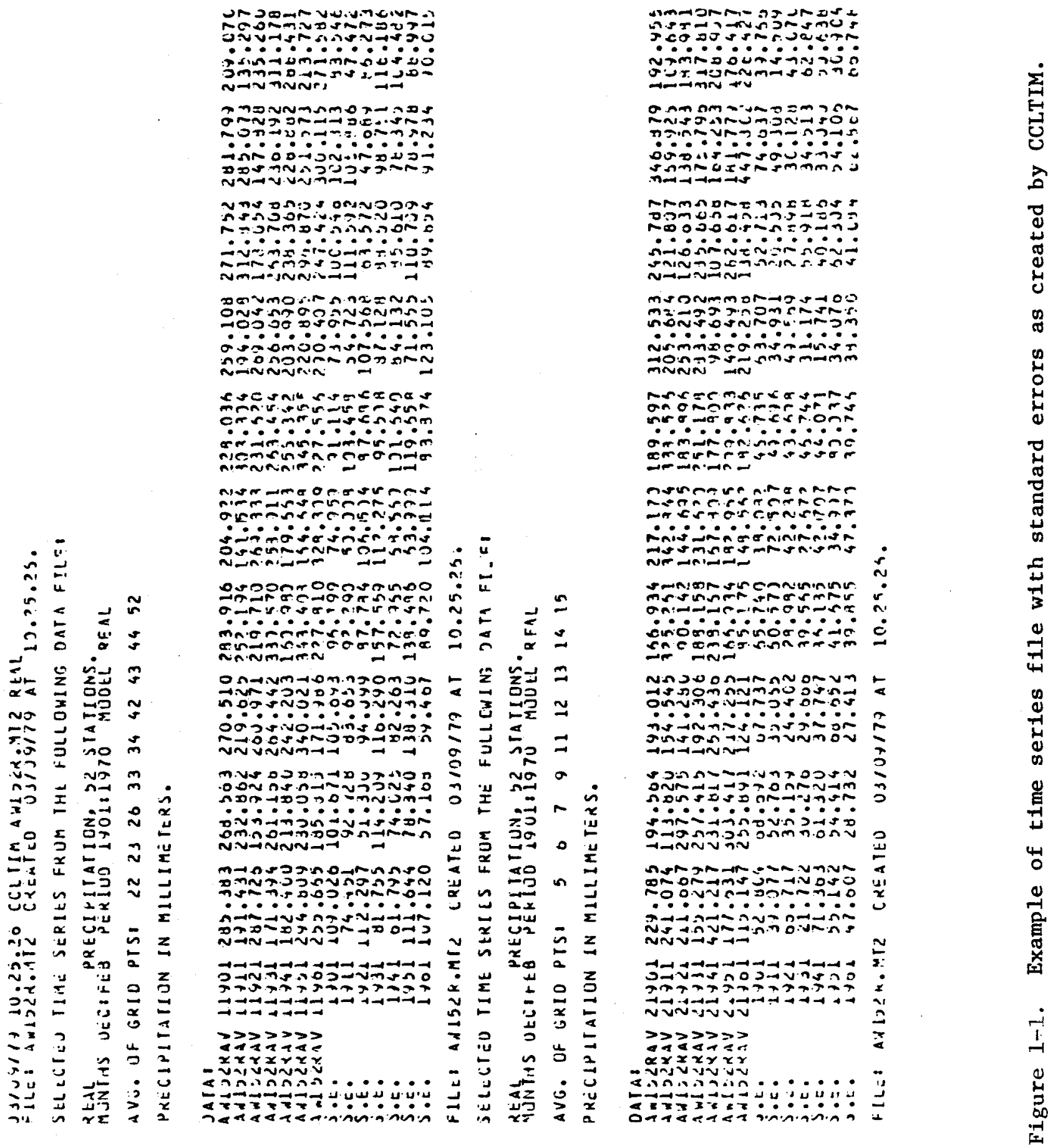


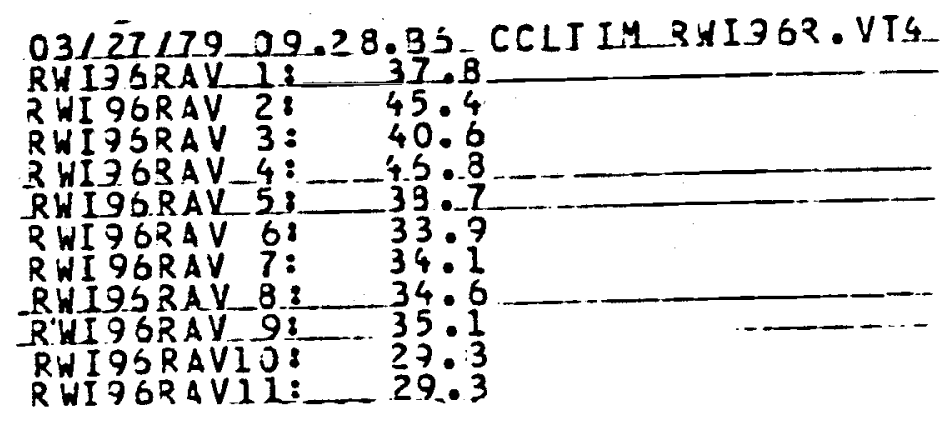

Figure 1-2. Example of average calibrated variance created by CCLTIM.

Figure 1-3. See page 1-25.

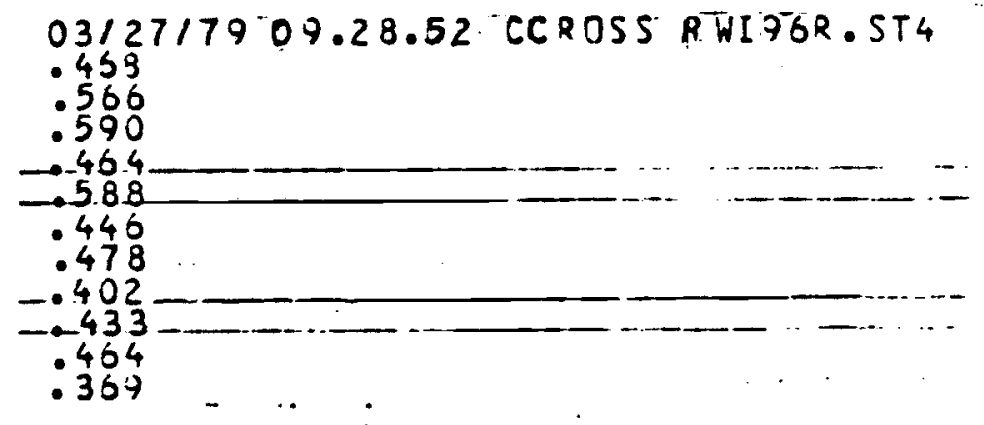

Figure 1-4. Example of scaling factor file created by CCROSS. 


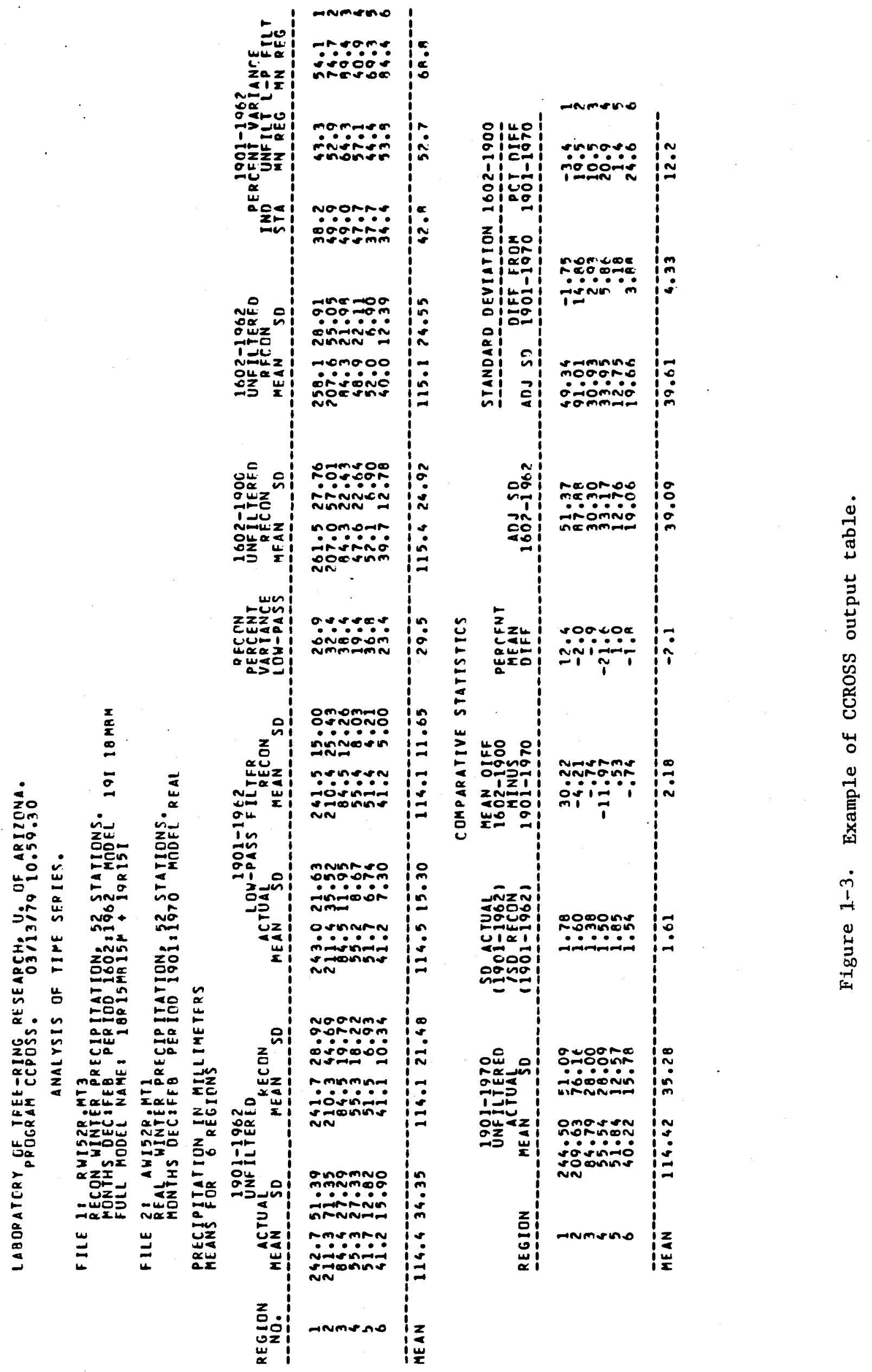




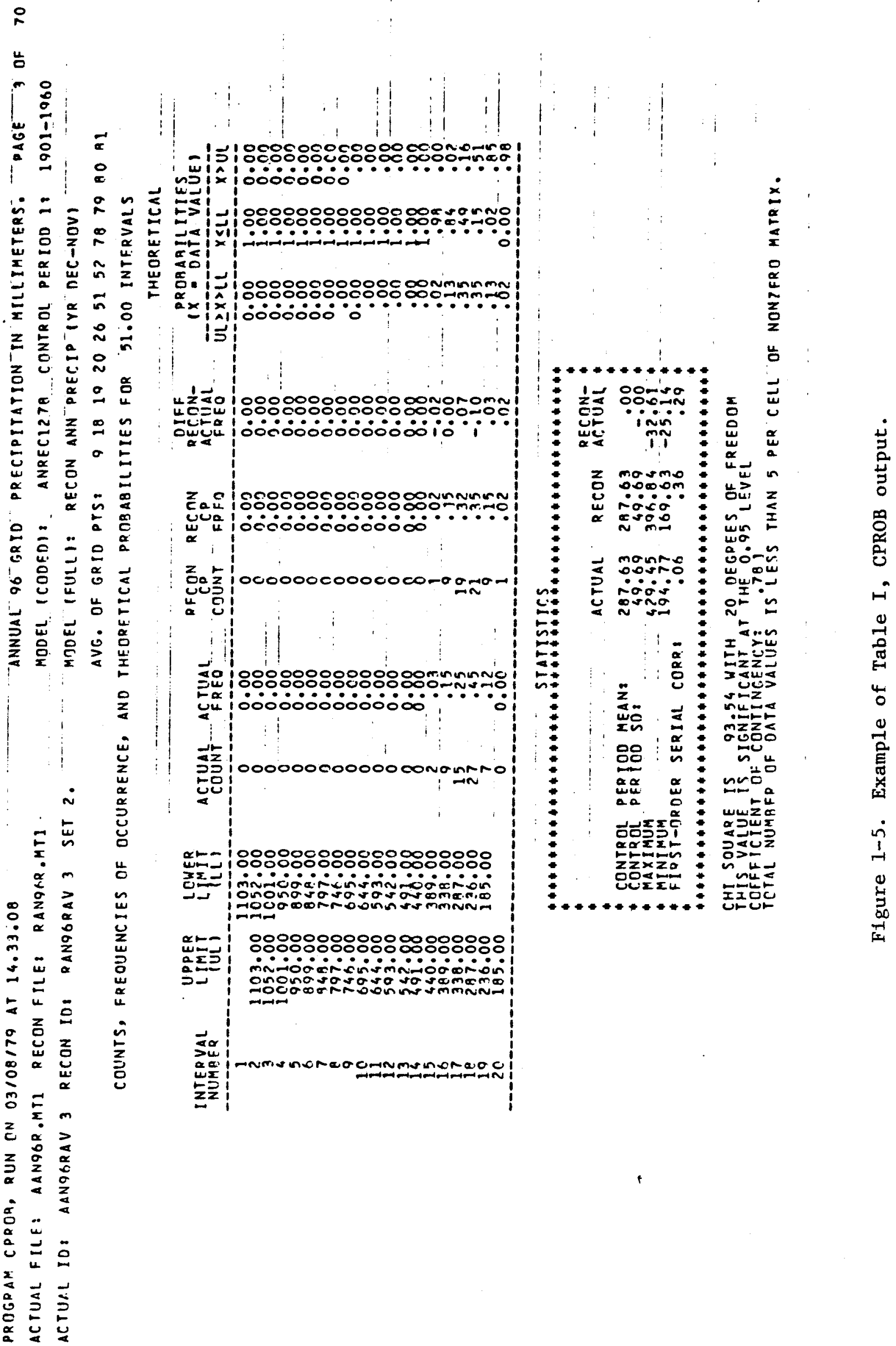




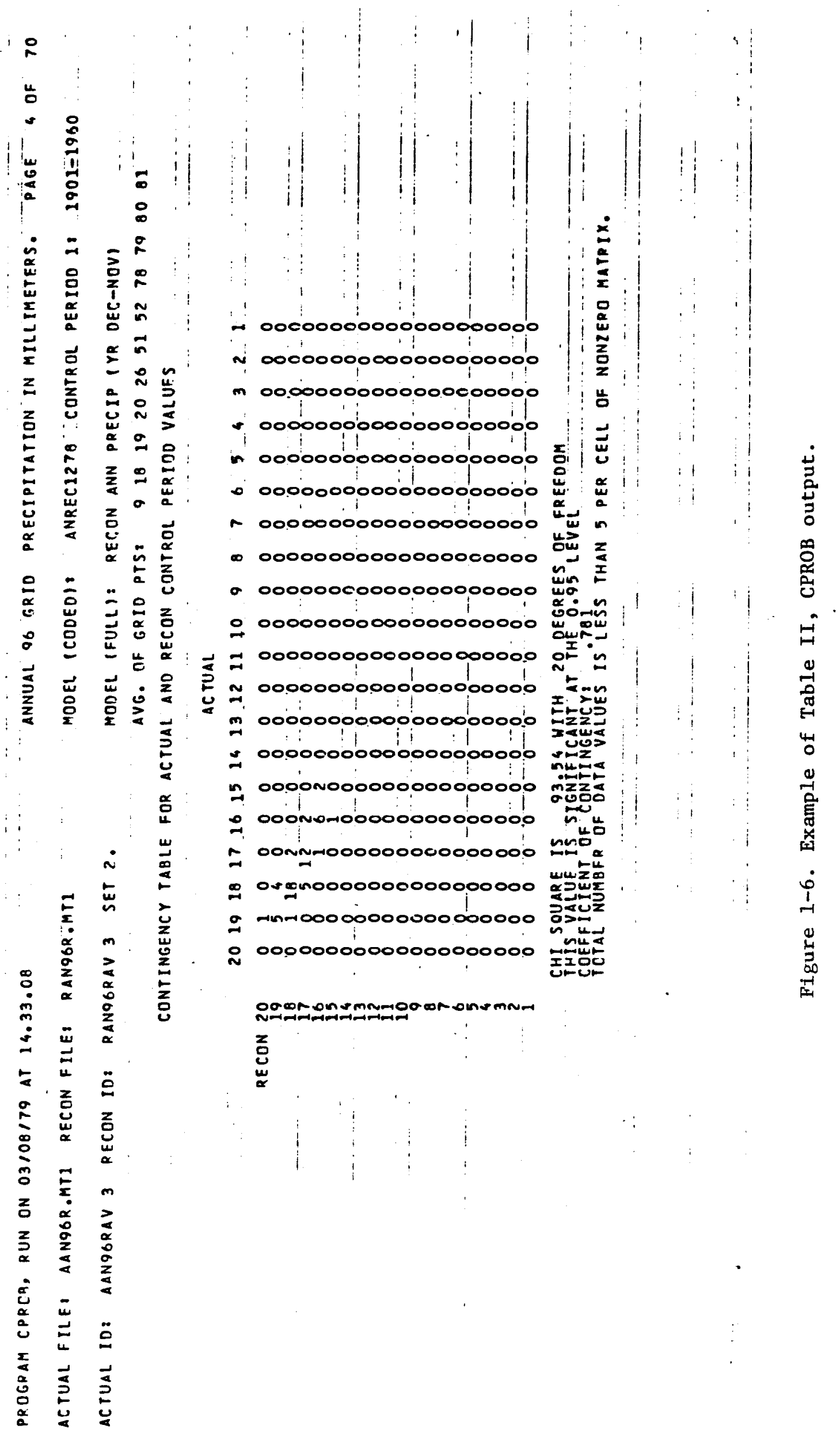




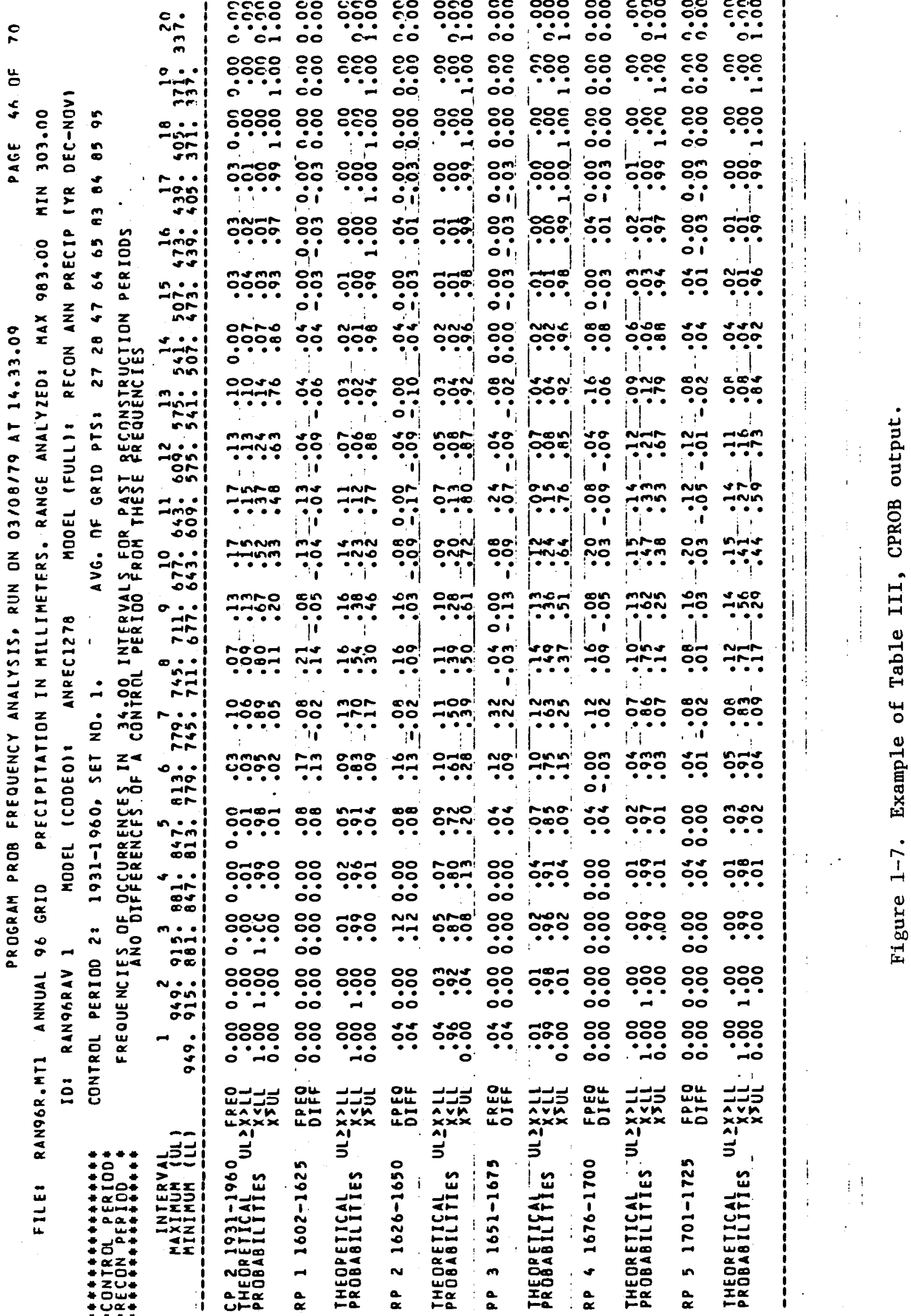




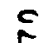

岂

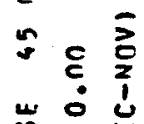

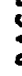

$\varepsilon$

$\geq \geq$

年|

$\therefore$ :

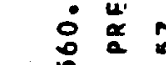

年|

年|

$\circ \geq$

$\frac{m}{2}$

$\dot{0} z \dot{m}^{\infty}$

:

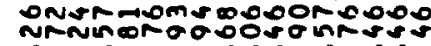

- -innono e - n-

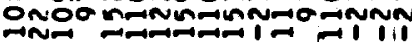

م no-memonnimorimmooo

: 足出

$\therefore \frac{2}{2} \alpha$

52

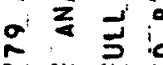

出

․

o.

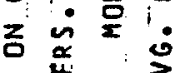

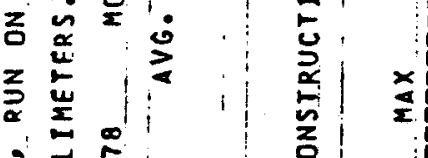

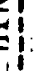

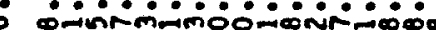

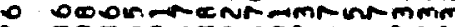

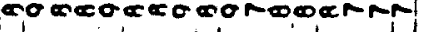

范

$\therefore \equiv$

$\approx x$ 出

$\geq z \stackrel{\alpha}{z} \dot{0}$

5

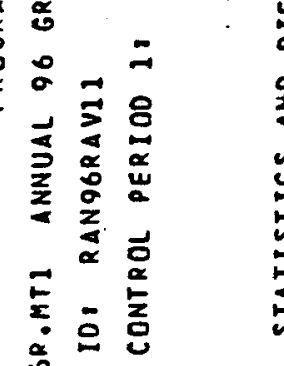

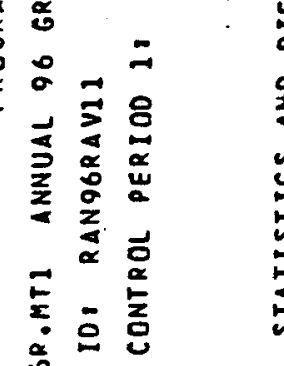

这

运吉点

a

过

4 这一

远

产

뭉

i:

ul i ji i l

cooxommmmomoommos

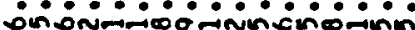

seNN10

o gesanmonroomponós

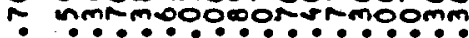

- inno

$\Rightarrow$ minnmanm

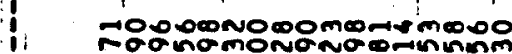

I $\quad \cdots \ldots \ldots \ldots \ldots \ldots$

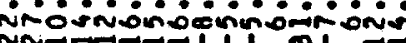

N1, 1 !

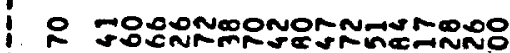

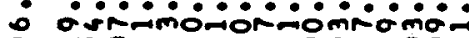

ZNㅛ

i

4

onanmornonmonmma

monm

(1...

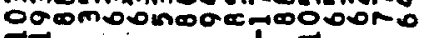

nommoomunsosarmant

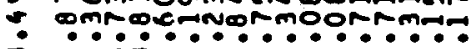
inominnons -nimion 1000000000000000

二-19

$*+1$

- non-nomomonoo0000

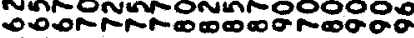

11111117111

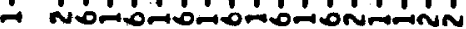
onntonin oñ

$\stackrel{\check{2}}{2}$

- rnmunormoomuminnor

- abanababababana

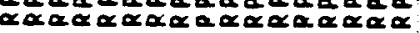

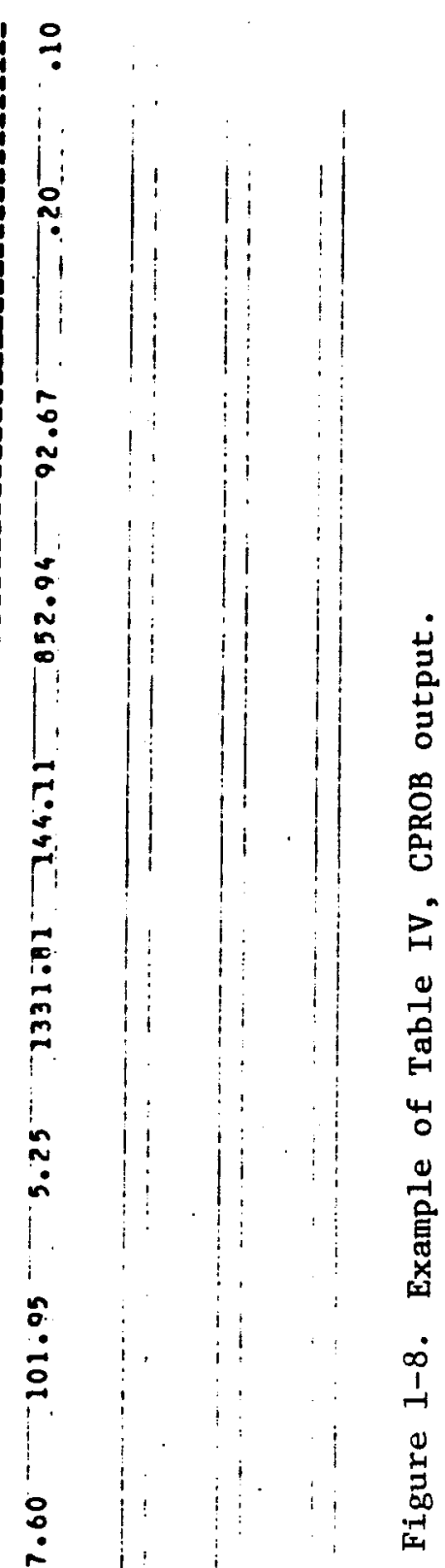




\section{APPENDIX 2}

Statistics for Reconstructions by 25-Year, 100-Year, 300-Year, and 360-Year Intervals as Compared to 1901-1961 Statistics 


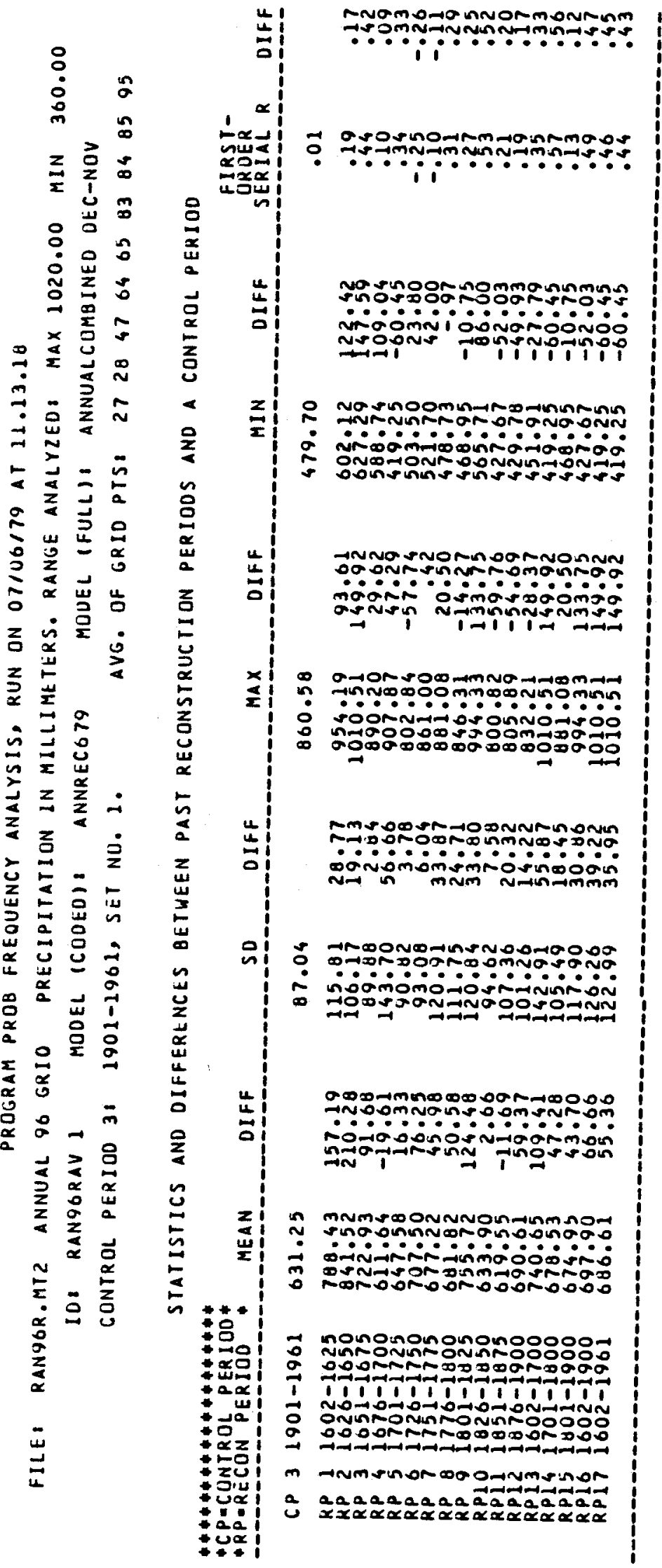




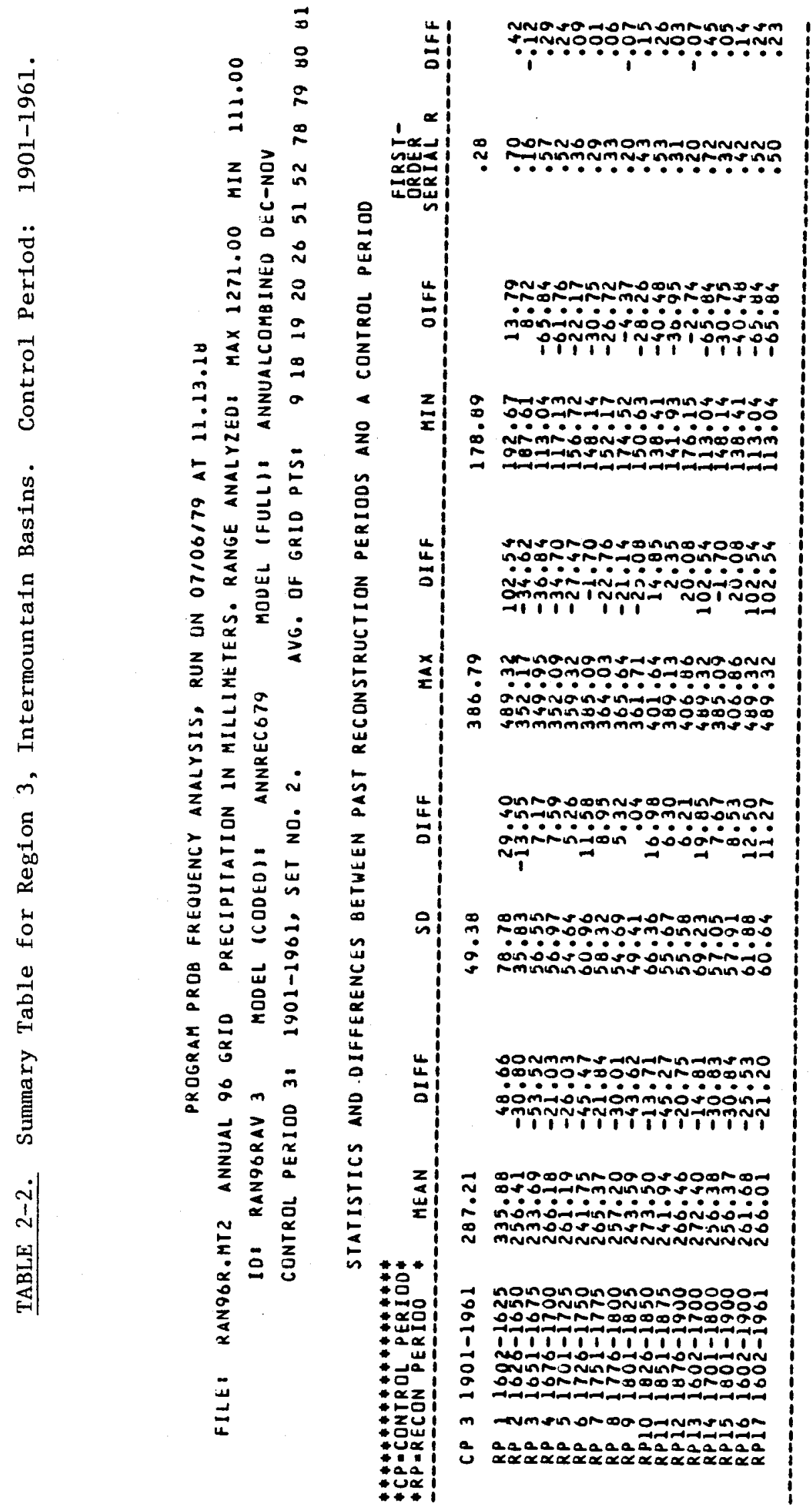




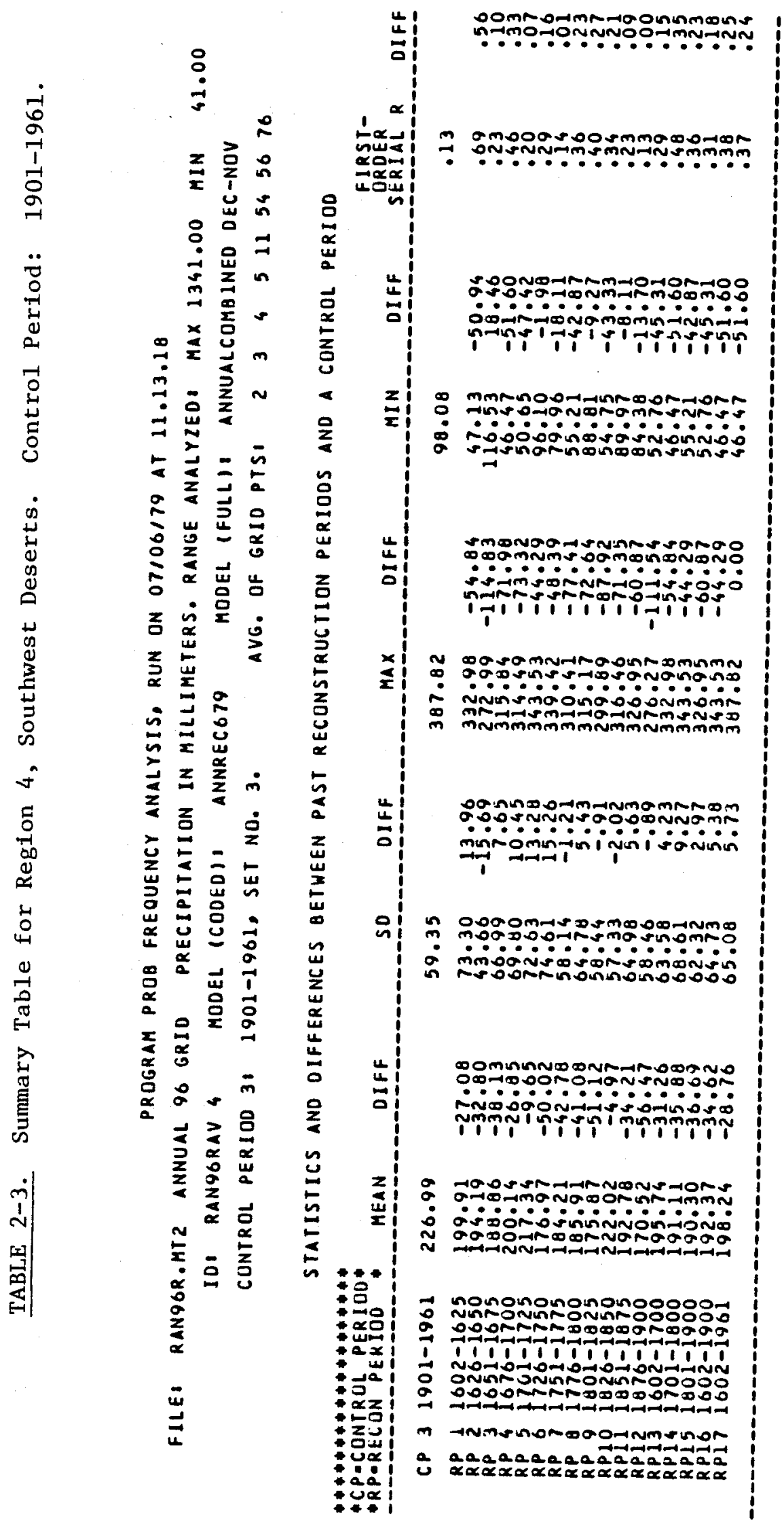




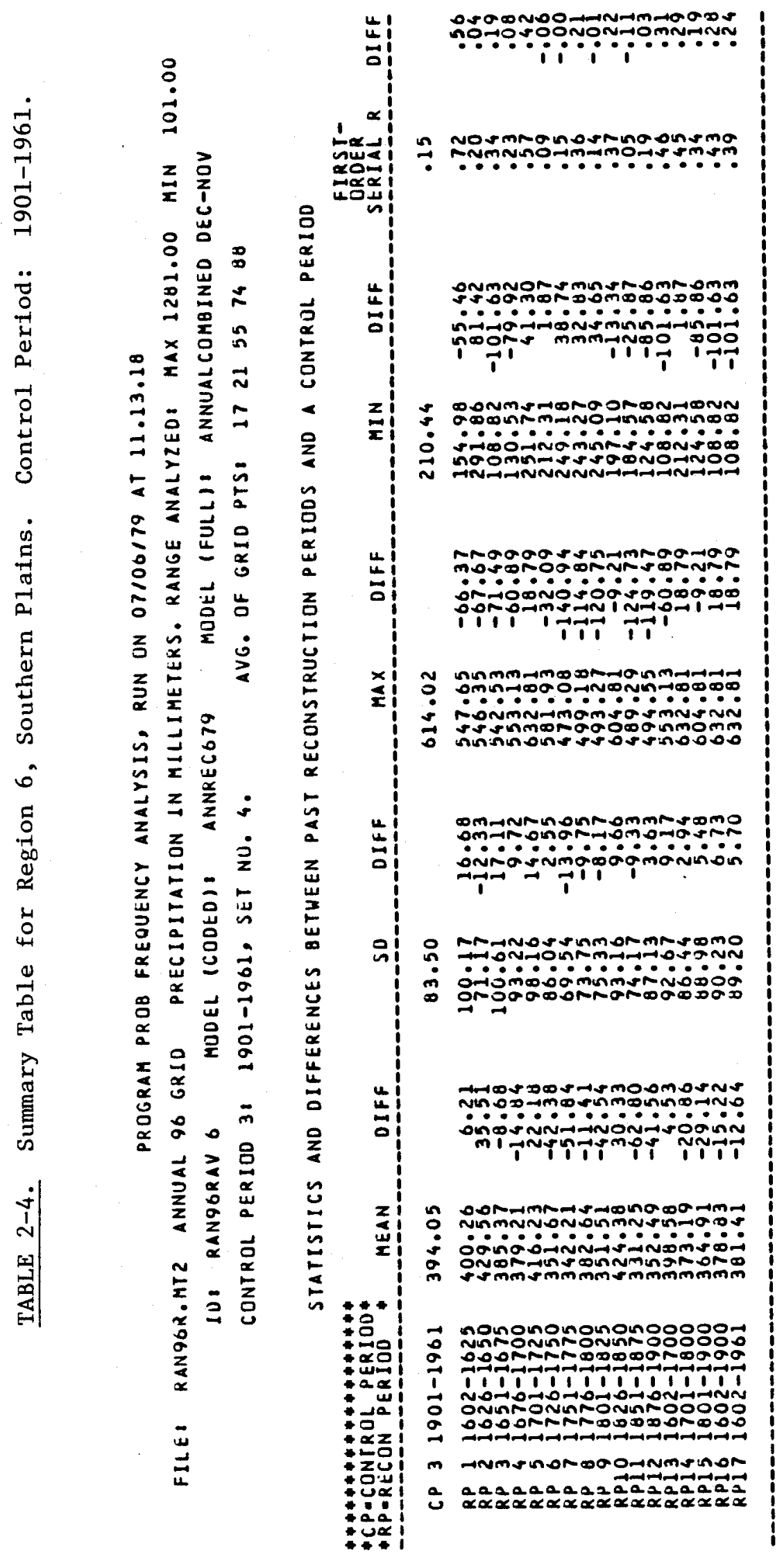




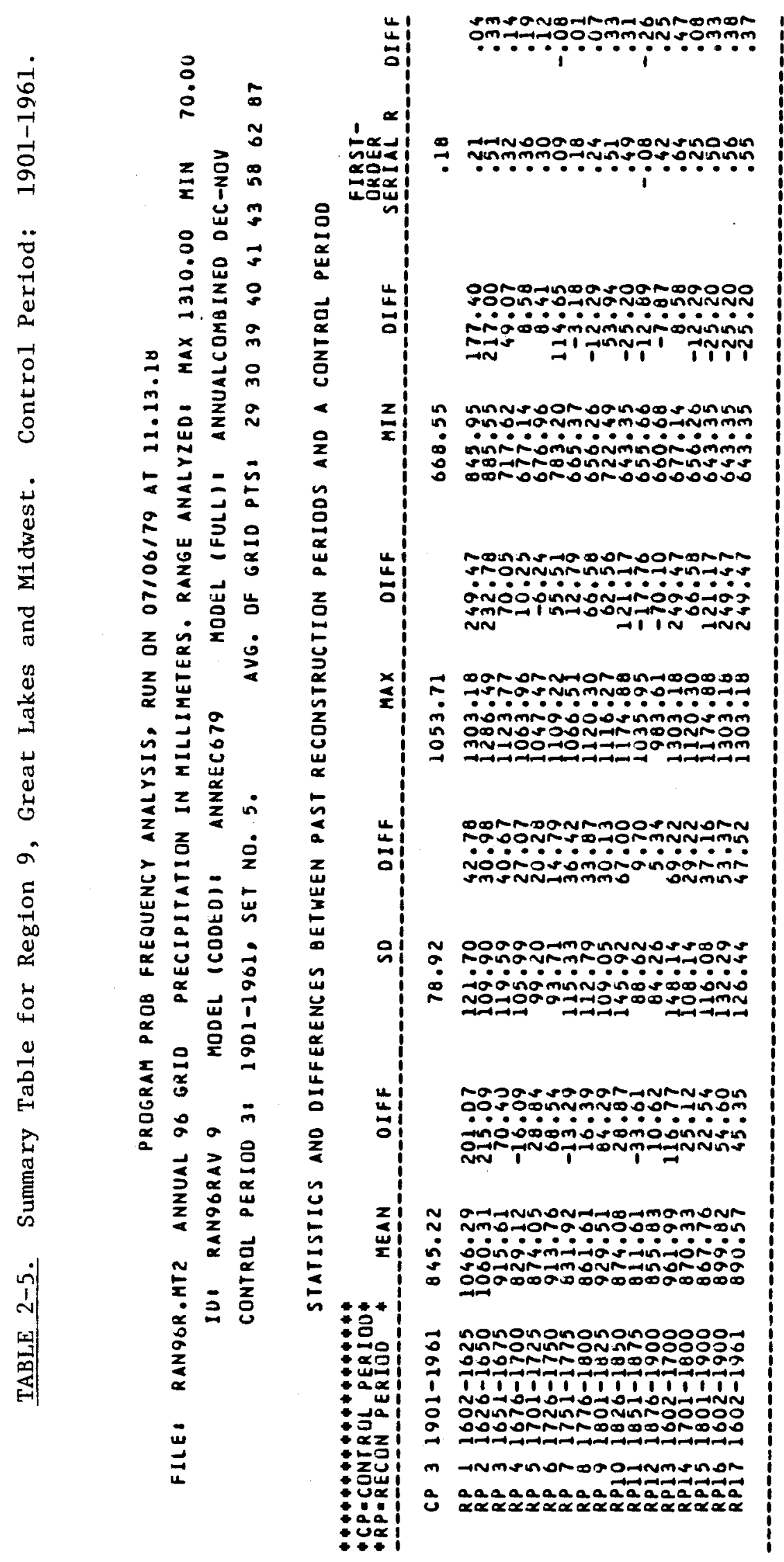




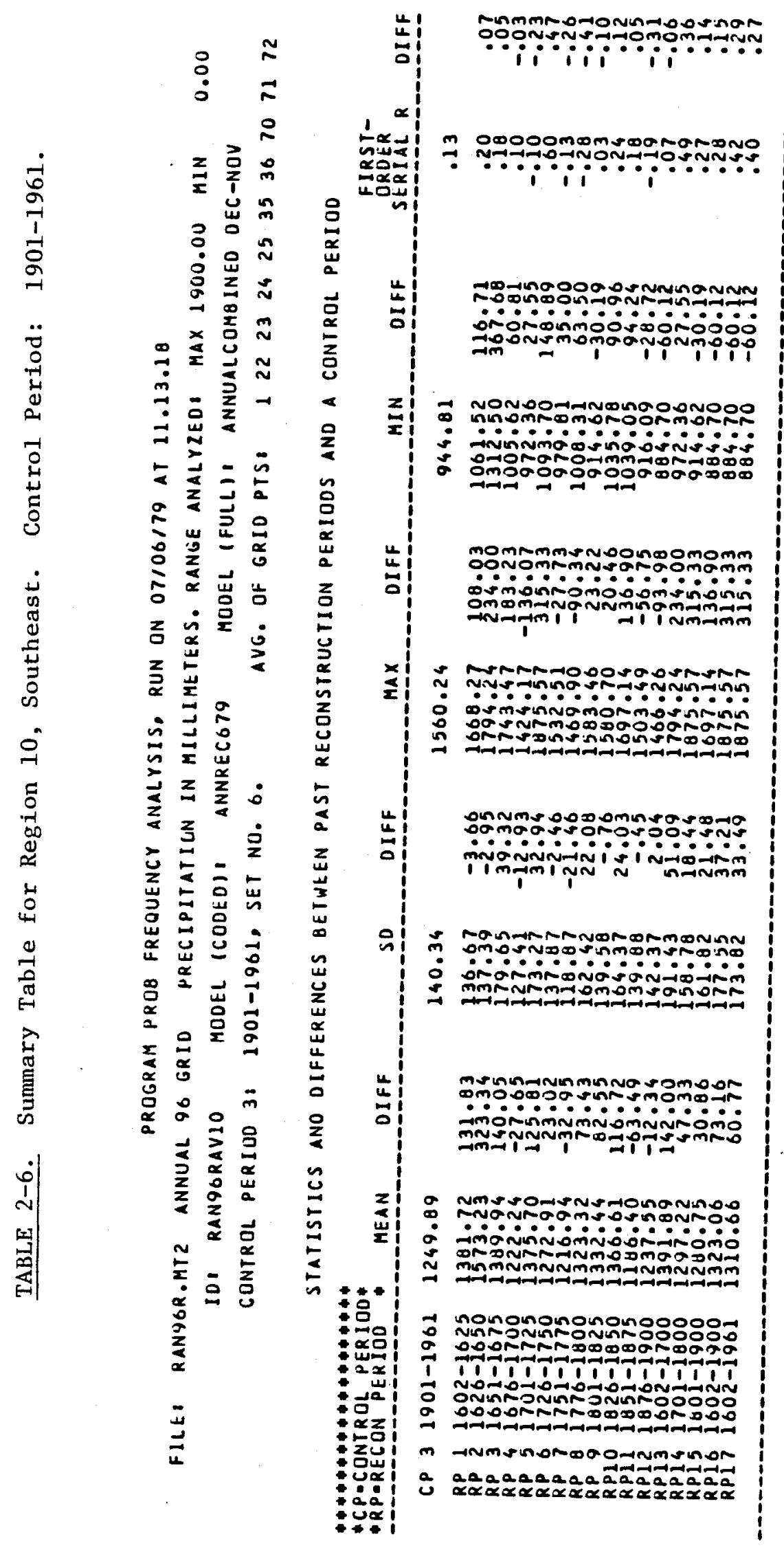




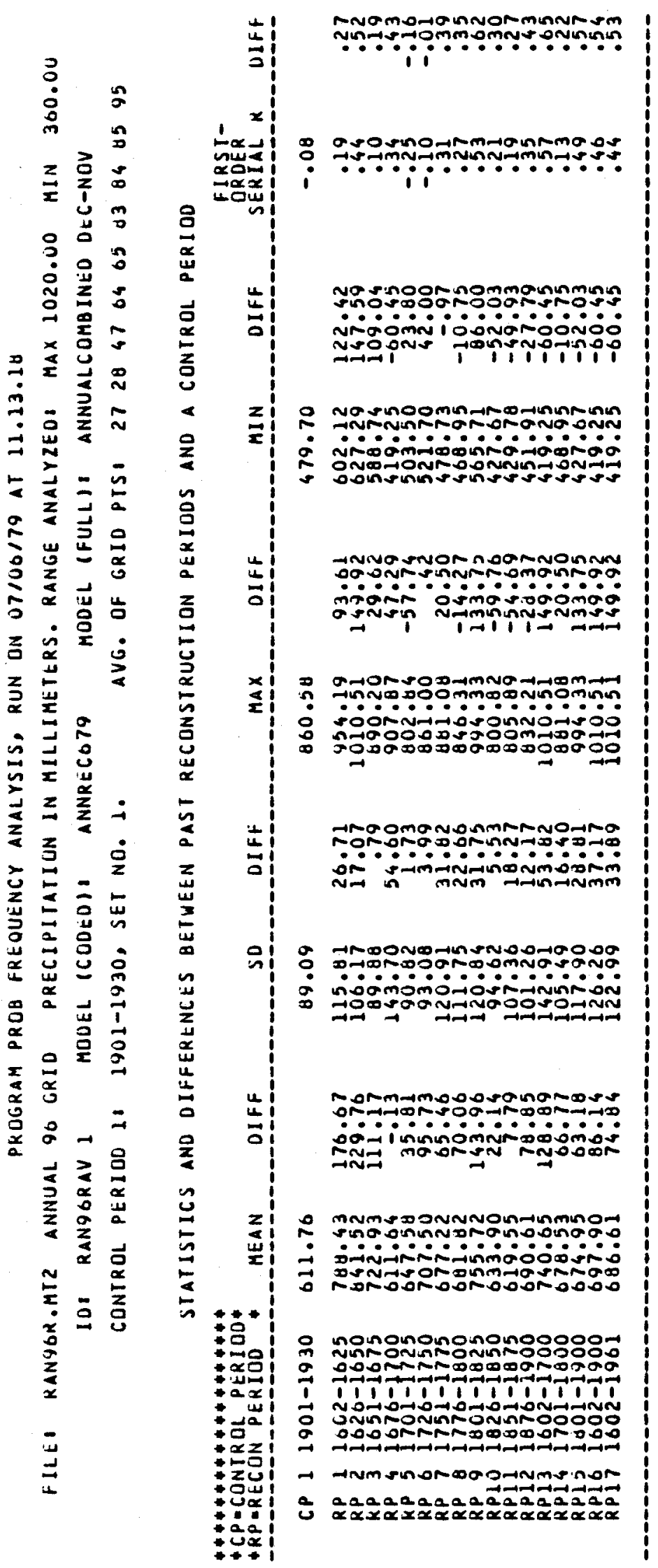




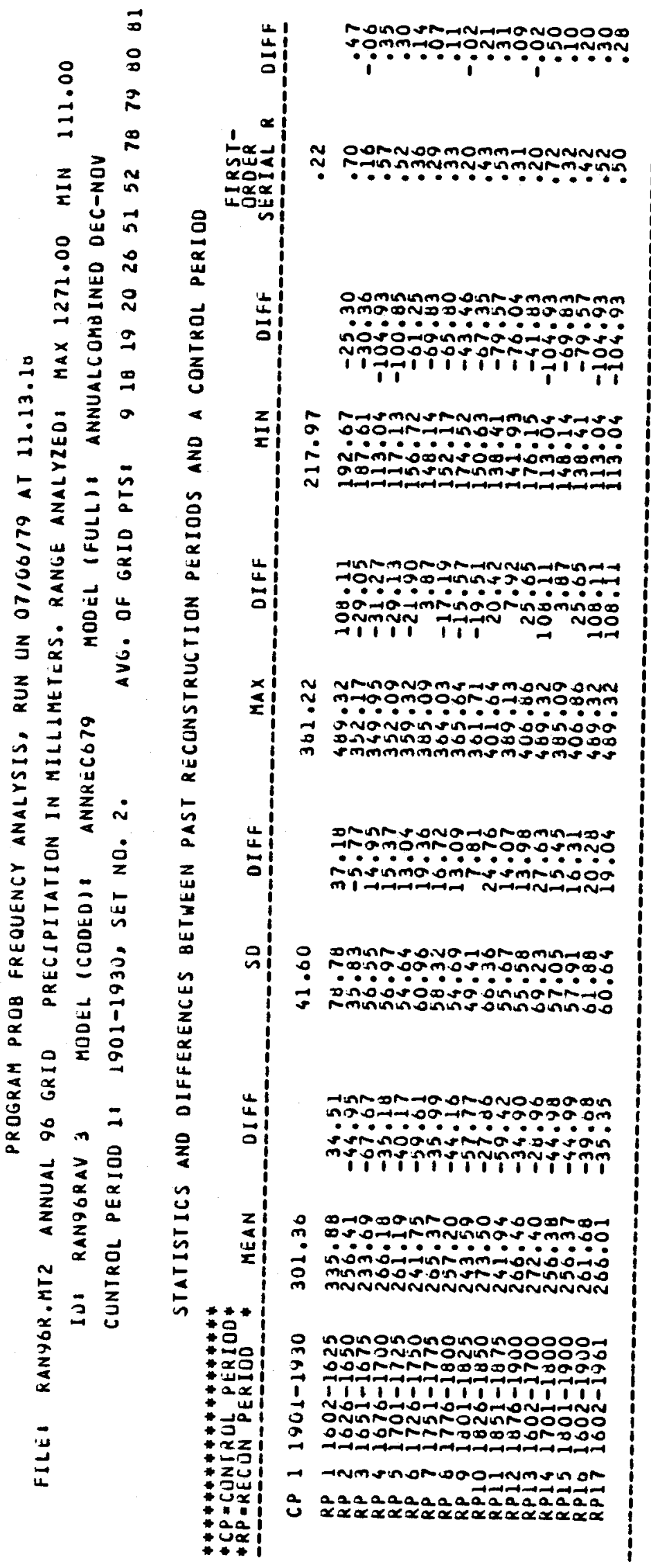




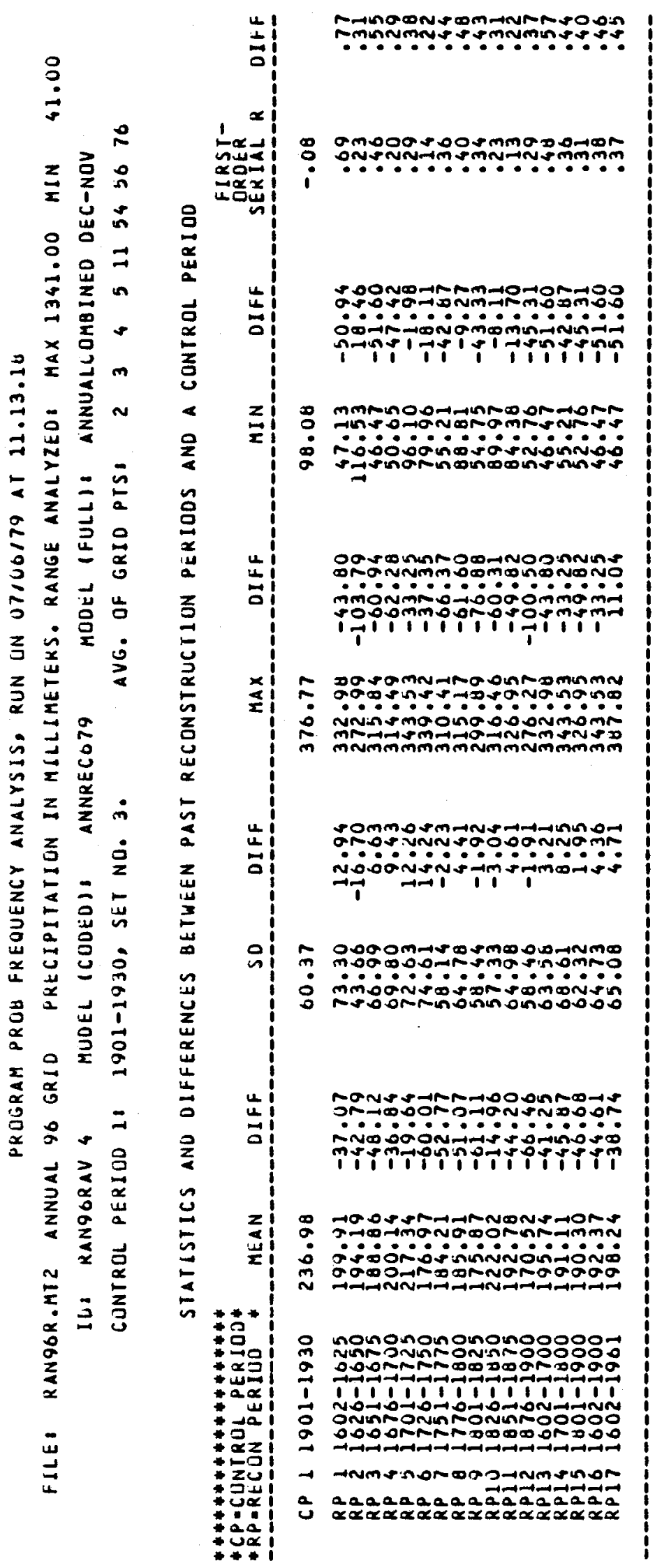




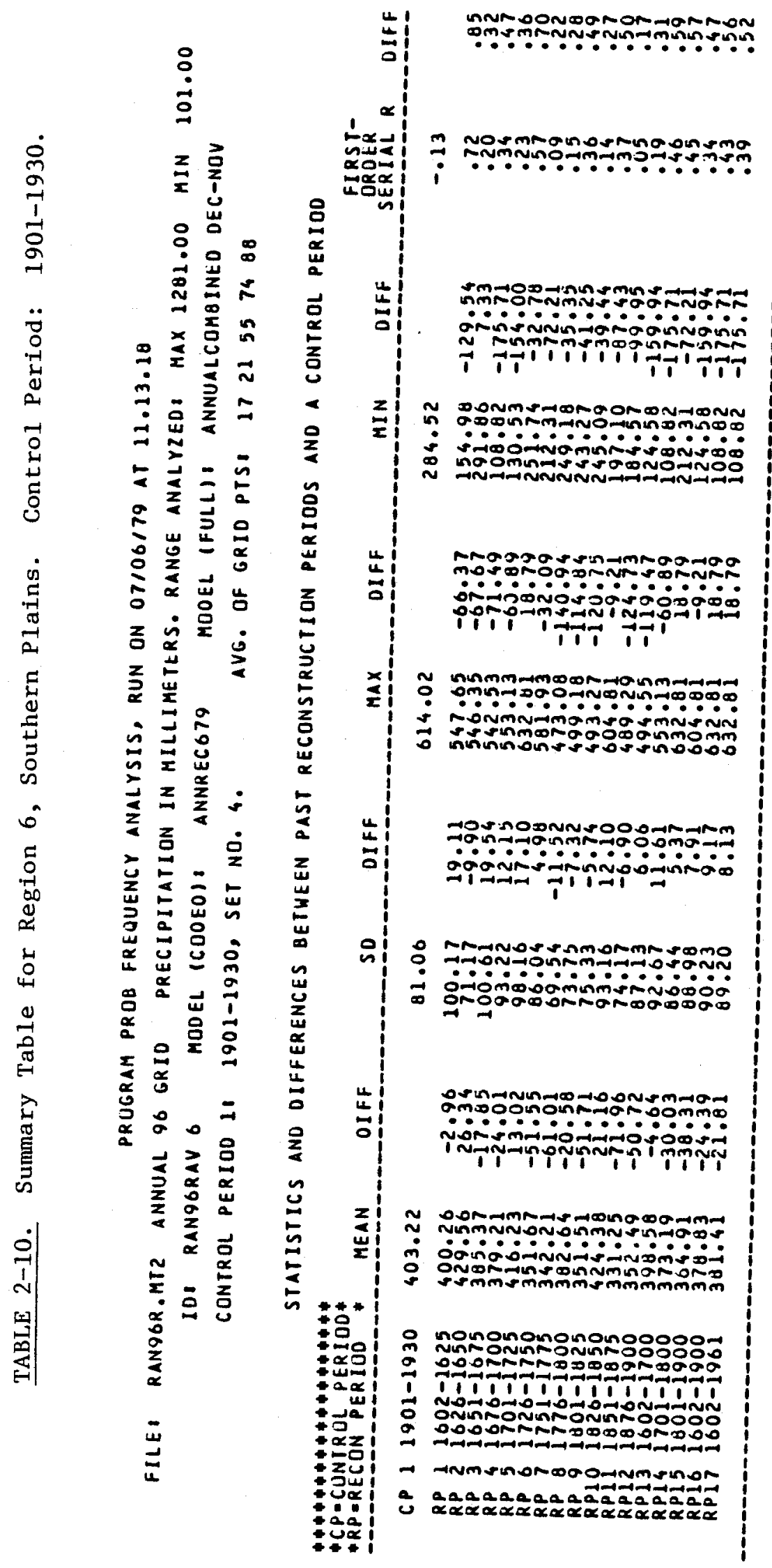




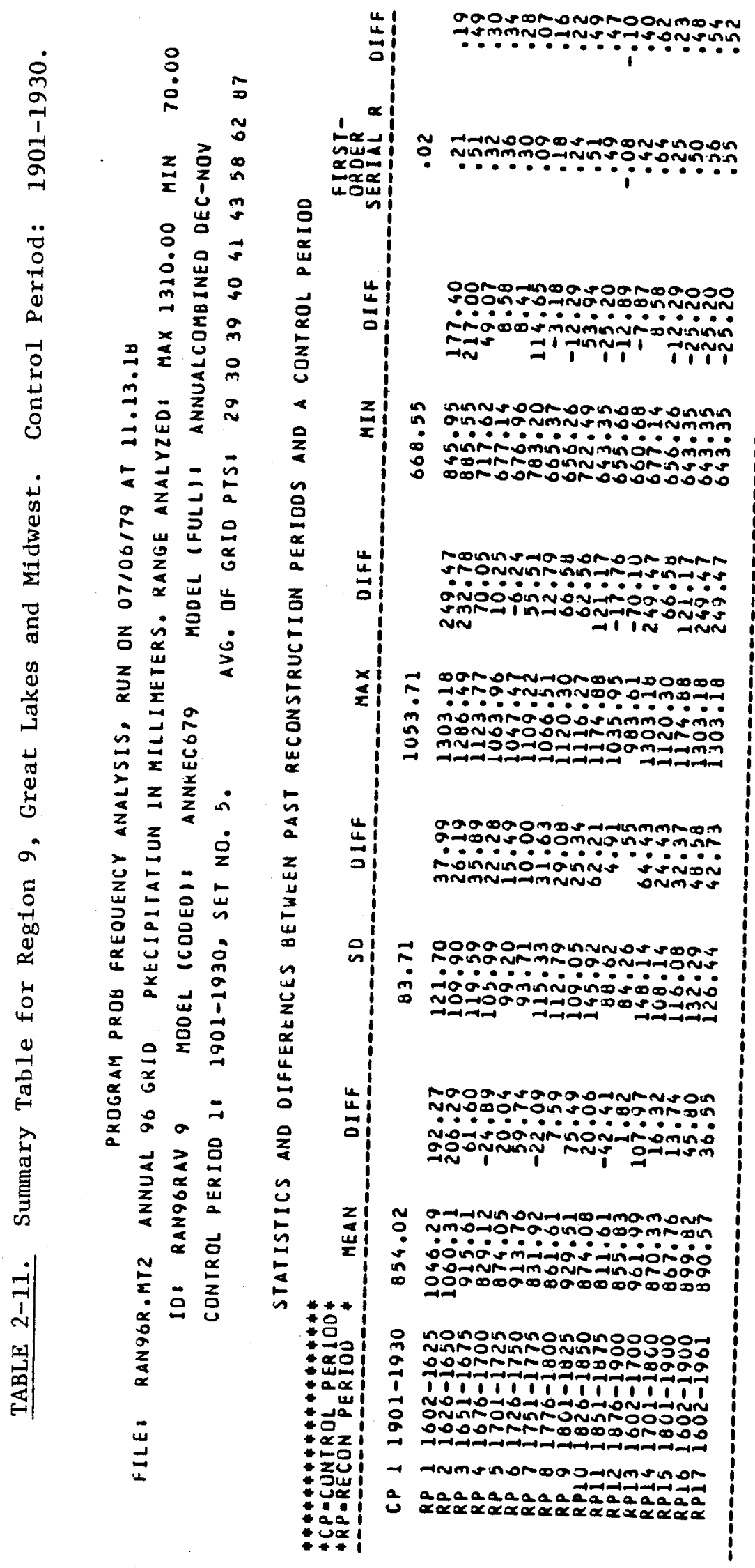




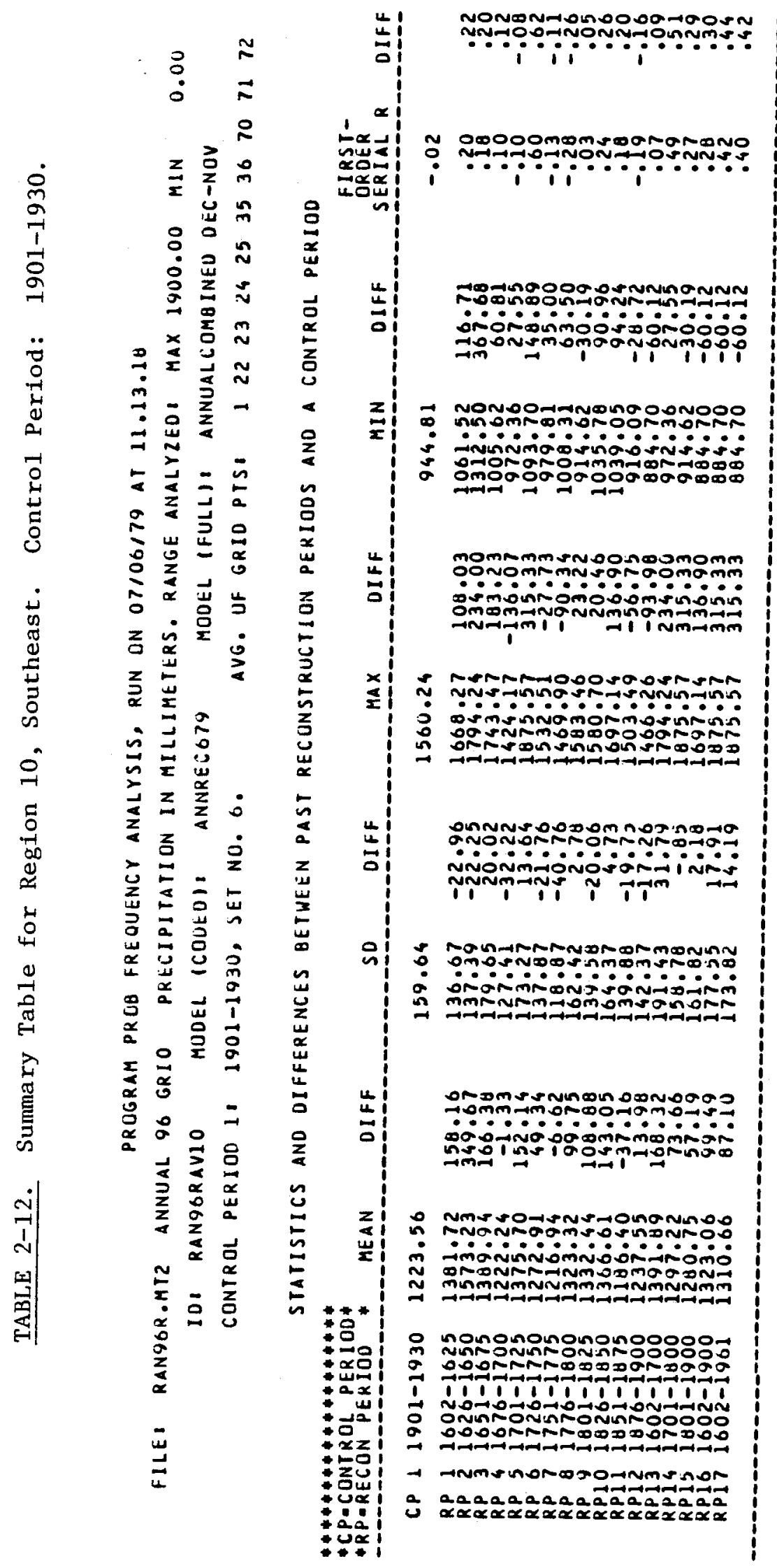




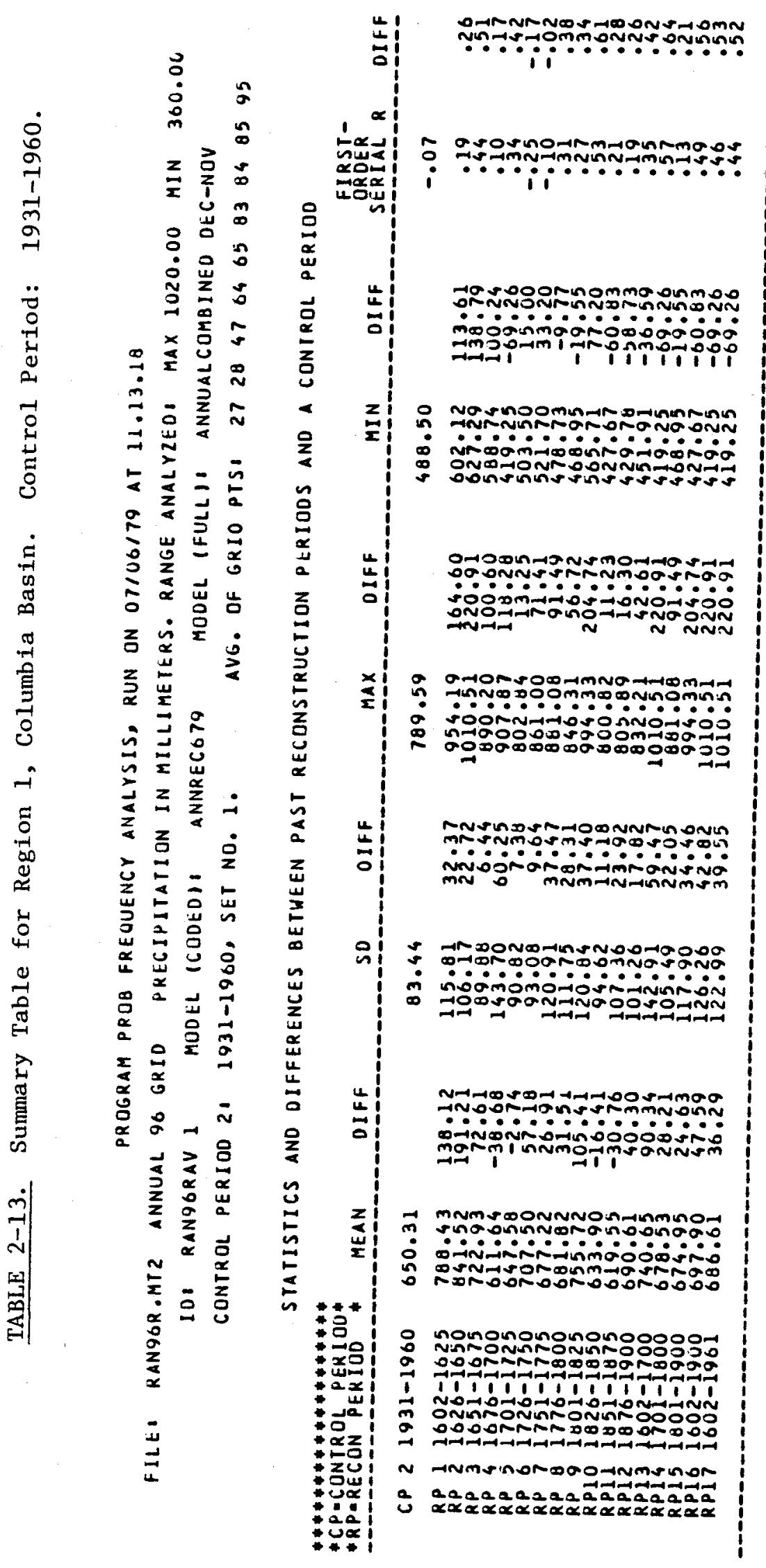




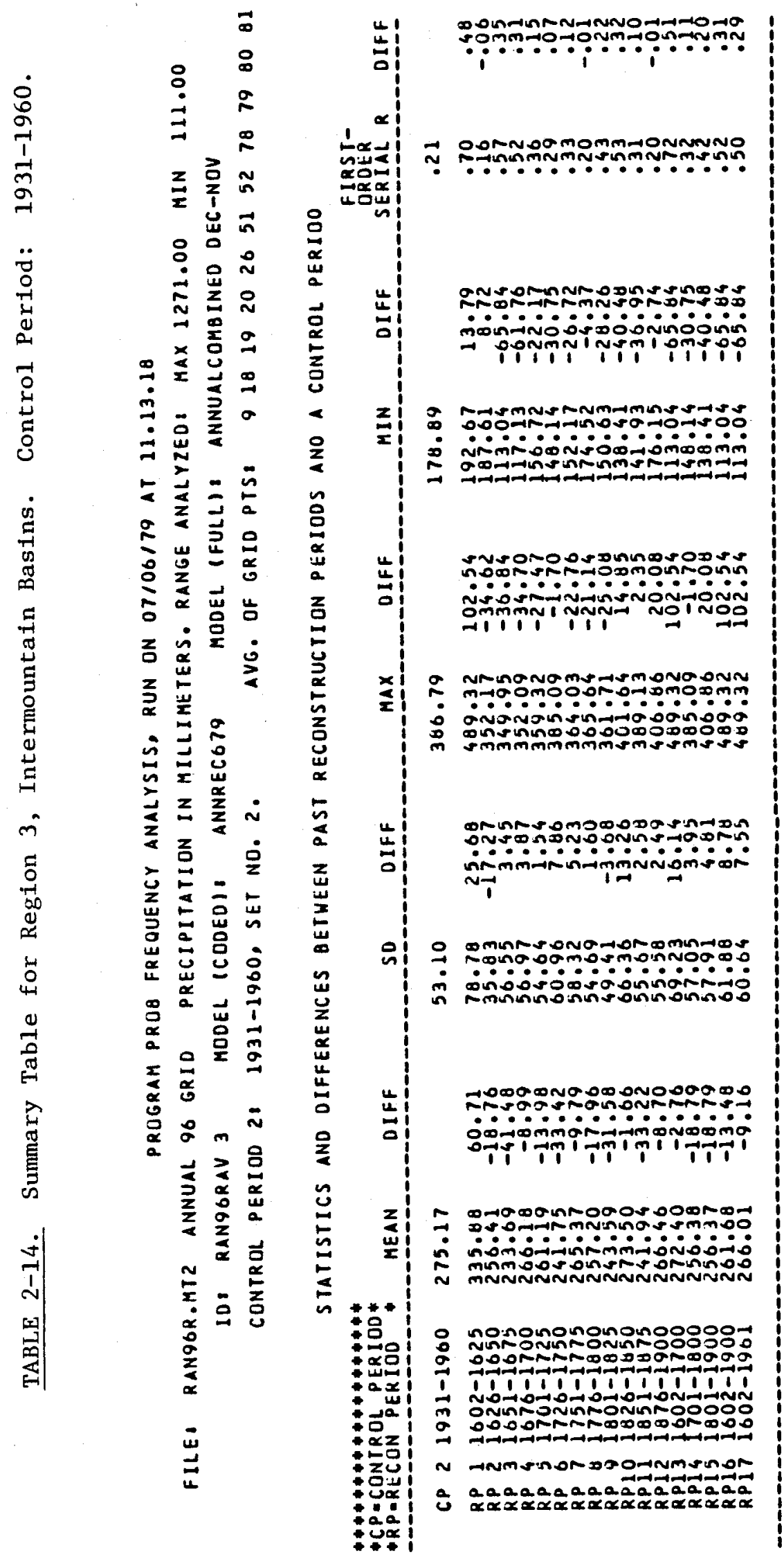




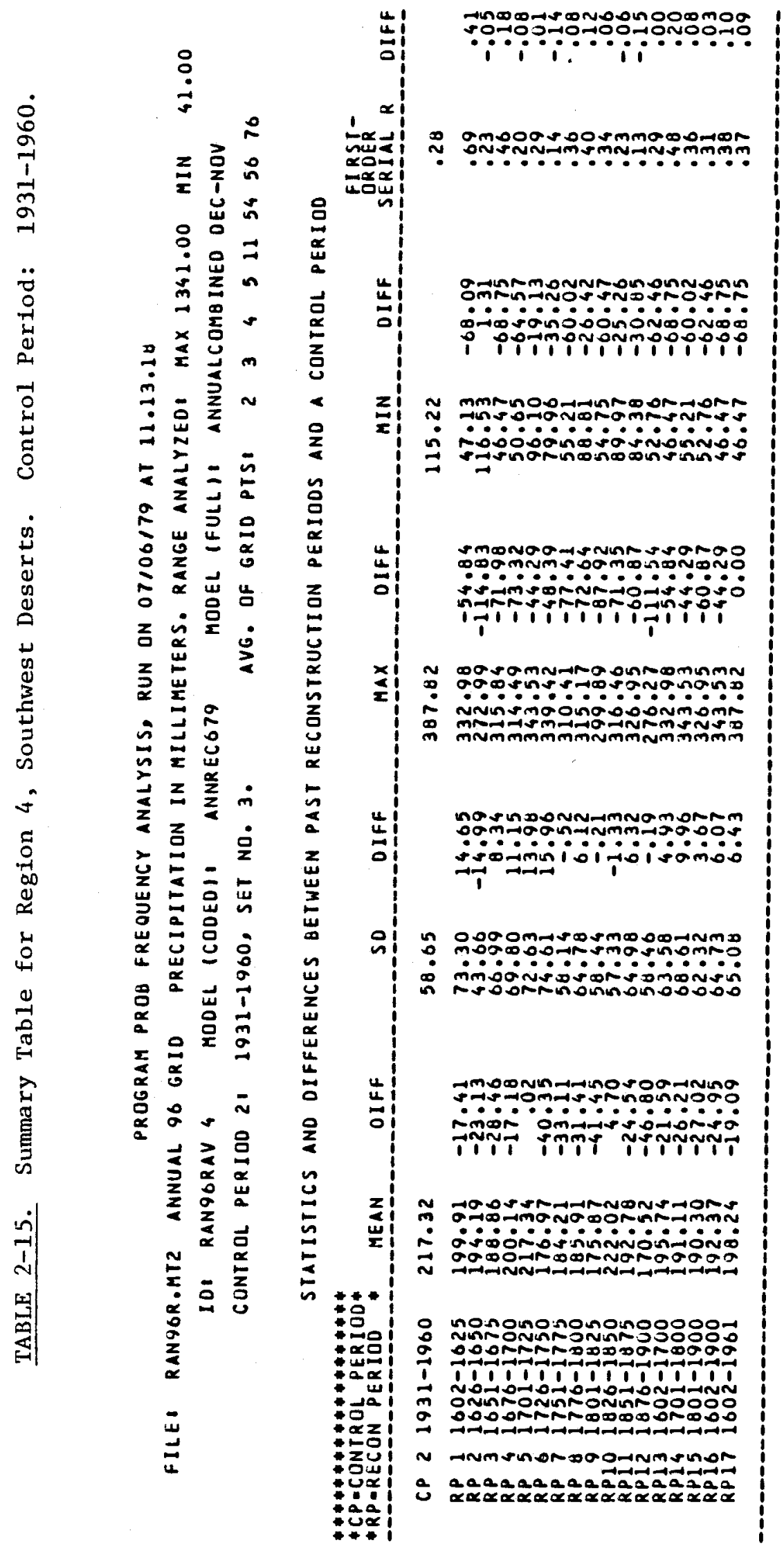




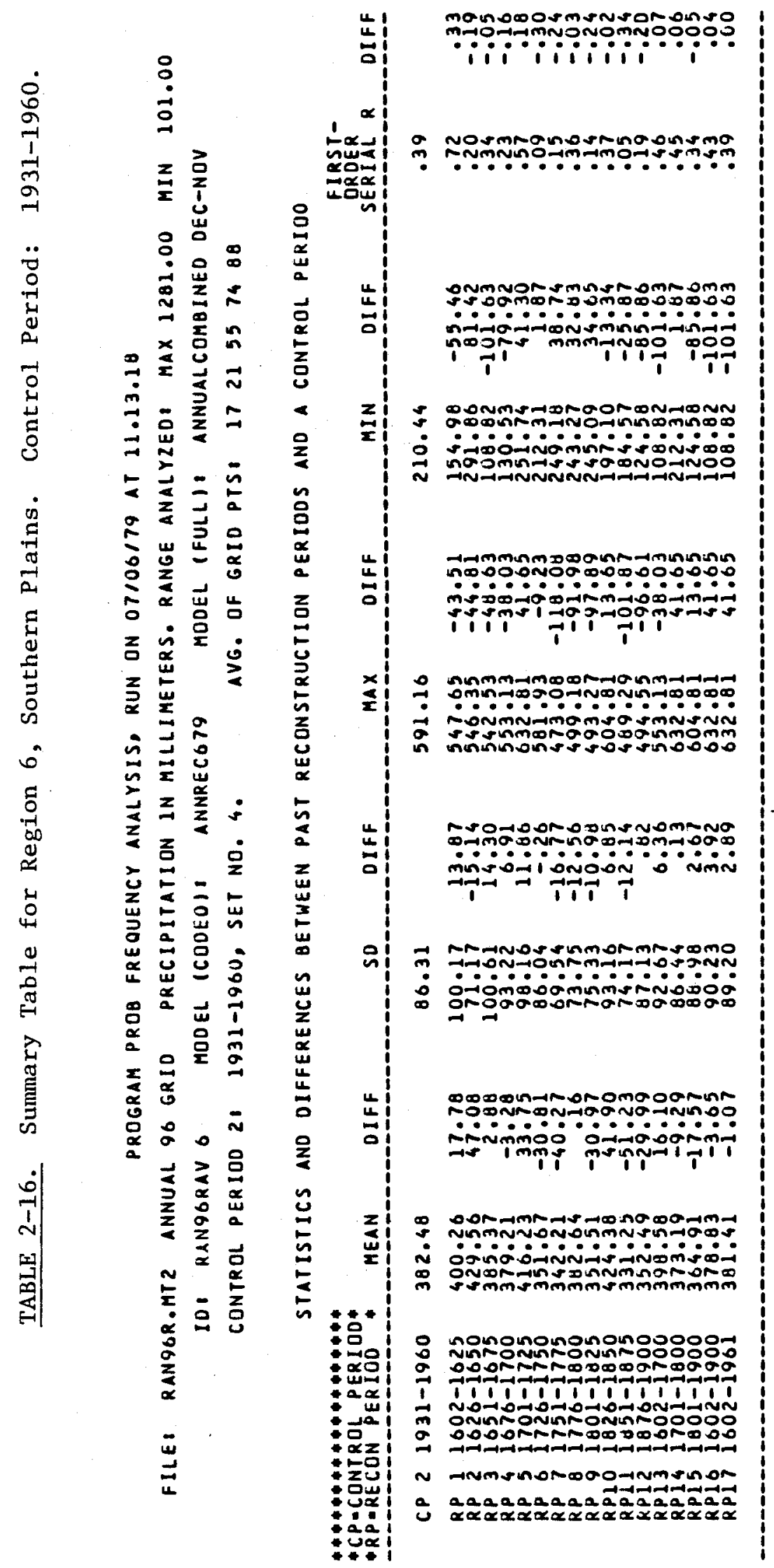




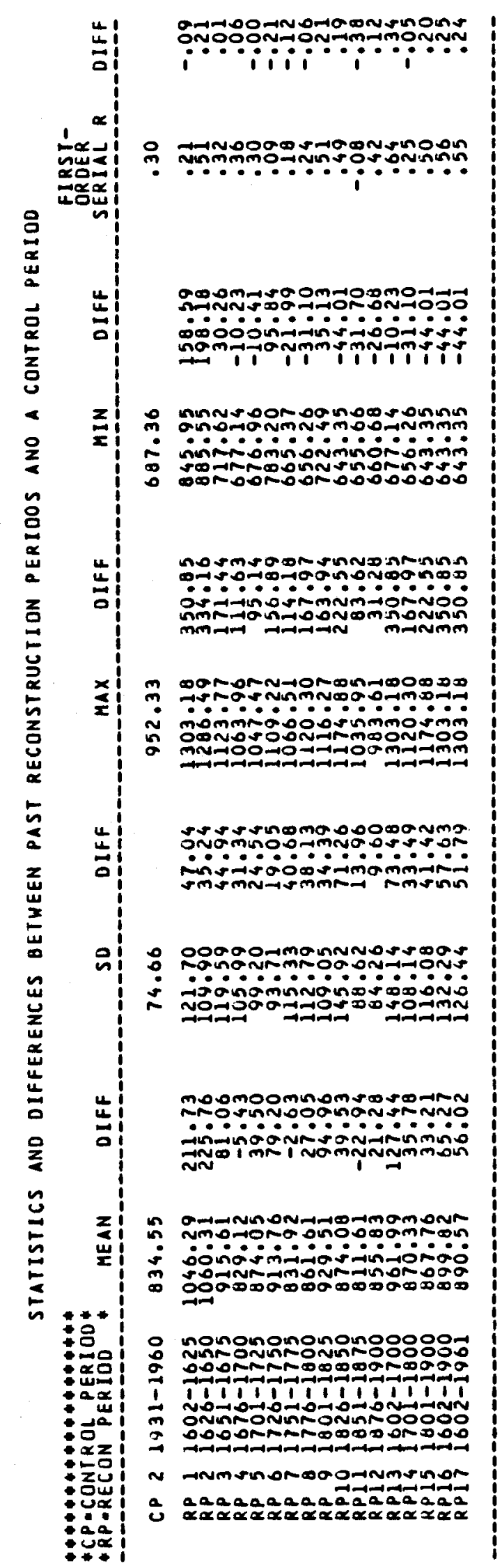




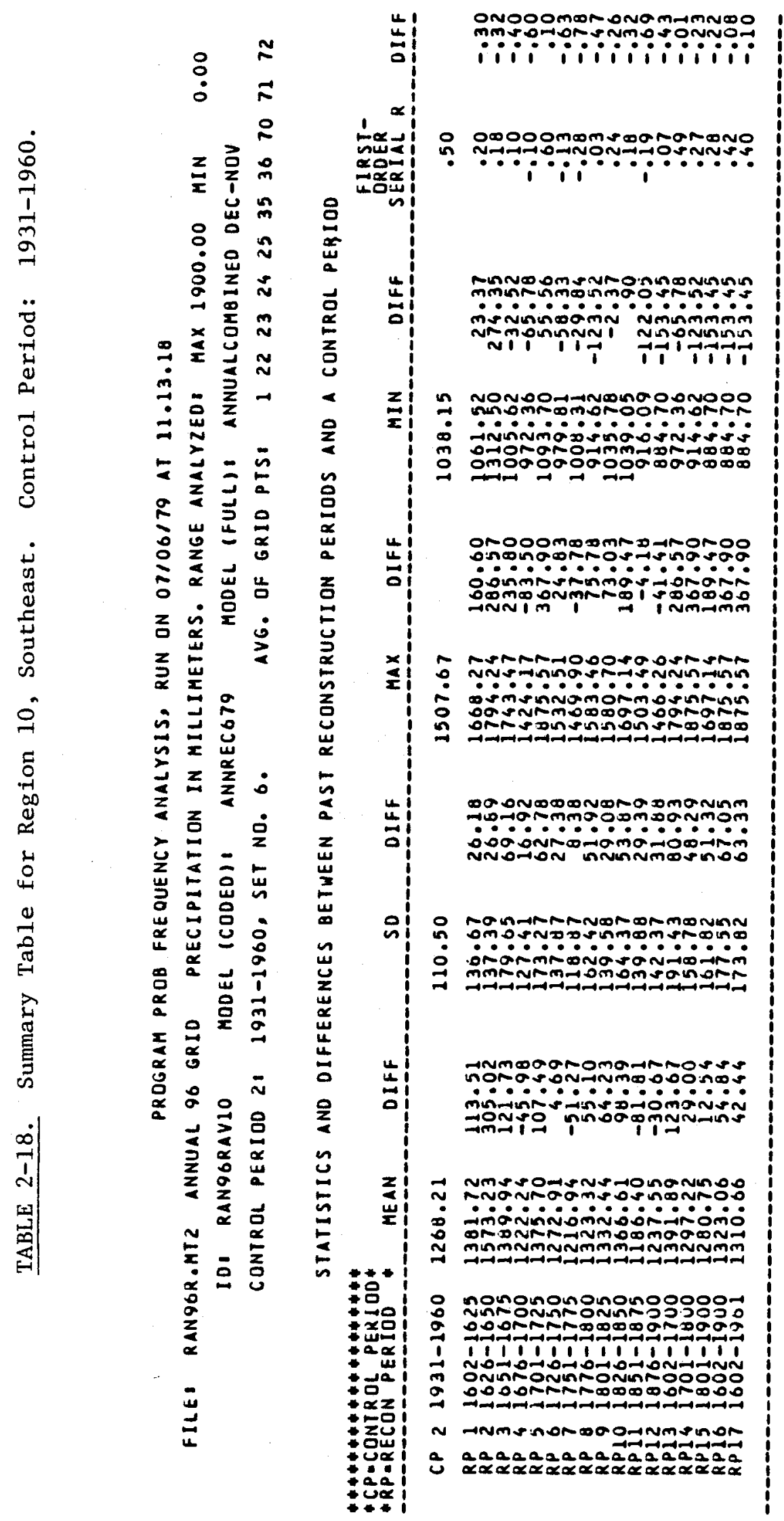

